\title{
Striving for Unwanted Goals: Stress-Dependent Discrepancies Between Explicit and Implicit Achievement Motives Reduce Subjective Well-Being and Increase Psychosomatic Symptoms
}

\author{
Nicola Baumann, Reiner Kaschel, and Julius Kuhl \\ University of Osnabrück
}

\begin{abstract}
Three studies investigated the relevance of affect regulation, stressful life events, and congruence between explicit achievement orientation and implicit achievement motive for subjective well-being and symptom formation. According to personality systems interactions (PSI) theory, stressful life events were expected to reduce motive congruence when the ability to self-regulate affect was impaired (i.e., state orientation). Consistent with expectations, the State Orientation $\times$ Stress interaction predicted incongruence in healthy participants (Studies 1 and 3) and in patients (Study 2). Furthermore, incongruence partially mediated the direct State Orientation $\times$ Stress effect on subjective well-being (Studies 1 and 3 ) and the course of psychosomatic complaints over 3 months (Study 2). In Study 3, the experimental induction of threat reduced motive congruence in state-oriented participants compared with an acceptance condition. Findings underscore the importance of assessing motive congruence as a "hidden stressor" and validate a new operant multimotive test.
\end{abstract}

Keywords: implicit motives, achievement orientation, self-regulation, psychosomatic symptoms, PSI theory

Do you know the story of a young man lying content underneath a tree when a busy old man comes walking by, curious about why the young fellow doesn't work? When asked, "What is it good for?" the old man comes up with many good reasons such as earning money, learning something new, and testing one's own abilities only to hear the young man repeat his question, "What is it good for?" The old man explains that it is good to take challenges in order to grow as a person and to feel proud about solving problems and accomplishing something. Again, the young man repeats his question, "What is it good for?" The old man becomes irritated and argues that he could lie back some day and feel content about his life. "But that is exactly what I am doing already!" the young man replies.

Subjective well-being and psychological health are influenced by many factors. On the one hand, stressful life events have been proposed as potential triggers of emotional problems and symptom formation (Holmes \& Rahe, 1967; Scully, Tosi, \& Banning, 2000). It is well established that stressful life events are especially detrimental to subjective well-being and positive affect when selfregulatory abilities to cope with stress are low (e.g., Chambel \& Curral, 2005; Folkman \& Moskowitz, 2004; Koole \& Jostmann, 2004; Kuhl \& Beckmann, 1994b; Showers \& Kling, 1996). On the other hand, motivational research has proposed that reaching per-

Nicola Baumann, Reiner Kaschel, and Julius Kuhl, Department of Human Sciences, University of Osnabrück, Osnabrück, Germany.

This work was supported by Grant DFG: Ku 377/22-2 from the German Science Foundation awarded to Julius Kuhl.

Correspondence concerning this article should be addressed to Nicola Baumann or Julius Kuhl, Department of Human Sciences, University of Osnabrück, Seminarstr. 20, 49069 Osnabrück, Germany. E-mail: nbaumann@uos.de or jkuhl@uos.de sonal goals is an important predictor of subjective well-being (Emmons, 1986; Martin \& Tesser, 1996). However, not all personal goals and motivational concerns are equally adaptive in satisfying basic needs (Cox \& Klinger, 2002; Elliot, Sheldon, \& Church, 1997; Klinger, 1993). Motive dispositions moderate the effects of personal goals on emotional well-being (Brunstein, Schultheiss, \& Grässmann, 1998; Hofer \& Chasiotis, 2003): Personal goal orientations are associated with high emotional wellbeing when they are congruent with motive dispositions. In contrast, personal goal orientations are associated with low emotional well-being when they are incongruent with motive dispositions.

In the present article, we attempt to integrate the different lines of research mentioned above and show that motive-incongruent orientations can act as "hidden stressors" that partially mediate the direct relationship between affect regulation deficits and subjective well-being or symptom formation. We decided to begin the testing of our model in the achievement domain. In our model, motiveincongruent achievement orientation is set up as a mediating variable (i.e., affect-regulation deficits under stress $\rightarrow$ motive incongruence $\rightarrow$ reduced subjective well-being and symptom formation). Either type of motive incongruence (i.e., showing a high achievement orientation on a conscious level despite a low implicit achievement motive as well as showing a low explicit achievement orientation despite a high implicit achievement motive) are expected to have negative effects on well-being and health.

In the following paragraphs, we provide a theoretical analysis of the concept of motive incongruence because little is known about the factors that contribute to the formation of motive-incongruent achievement orientations. A functionally oriented approach personality systems interaction (PSI; Kuhl, 2000, 2001), is introduced, which purports to explain the mechanisms involved in motive incongruence. 


\section{Functional Localization of Explicit Orientations and Implicit Motives}

Implicit motives are measured by operant motive tests, such as Murray's (1943) Thematic Apperception Test (TAT). Participants are asked to write stories about pictures in which they can express personal fantasies without any self-reference or restriction due to actual life contexts. Therefore, operant and implicit motive tests are better qualified for assessing contents of preverbal developmental phases and manifestations of unconscious, affective dispositions that distinguish actual motive dispositions from motiverelated cognitive values or orientations assessed by explicit selfreport (deCharms, Morrison, Reitman, \& McClelland, 1955). Accordingly, the implicit and explicit motive measures are conceptualized as reflecting distinct motive systems that show distinct behavioral correlates (Biernat, 1989; deCharms et al., 1955; McClelland, 1980; McClelland, Koestner \& Weinberger, 1989; Spangler, 1992).

According to PSI theory (Kuhl, 2000, 2001), explicit goal orientations and implicit motives are associated with two different cognitive systems. Goal orientations are associated with the explicit verbal representation format of intention memory that is supported by sequential-analytical operations such as thinking and planning. Intention memory is a network of central executive functions involving the maintenance of an intended action in working memory (Baddeley, 1996) and the inhibition of premature initiation of an intention (Barkley, 1997; Fuster, 1989). The term is restricted to the representation of intentions in a higher order, abstract, typically symbolic and explicit format (cf. Kuhl \& Kazén, 1999). An explicit goal orientation, with its focus on outcome of an intended action, may be part of an action plan that is held in an active state in intention memory (Goschke \& Kuhl, 1993). In contrast, implicit motives are associated with implicit representations in extension memory, an extended semantic network operating according to connectionist principles and supported by intuitive-holistic processes (Beeman et al., 1994). This system permits an overview of extended semantic fields (Rotenberg, 1993), relevant episodes experienced (Wheeler, Stuss, \& Tulving, 1997), and integrated self-representations (Kuhl, 2000). According to PSI theory, extension memory provides access to implicit representations of one's needs, values, and wishes. Motive dispositions can be defined as "intelligent needs," that is, as implicit cognitive-emotional networks of possible actions (derived from autobiographical memory) that can be performed to satisfy basic social needs in a context-sensitive way across a variety of situations (Heckhausen, 1991; Kuhl, 2001; McClelland, 1980; Winter, 1996). According to this definition, motives can be considered the need-related part of the implicit self-system (Greenwald \& Banaji, 1995), which in turn can be regarded as the self-related part of extension memory. ${ }^{1}$

Two modulation assumptions of PSI theory state that positive and negative affect modulate the activation of cognitive systems: First, the inhibition of positive affect is assumed to activate intention memory, analytical strategies, and problem solving because behavioral routines to reach a goal have not been successful and need to be revised (Kuhl \& Kazén, 1999). Conversely, activation of intention memory (e.g., facing difficulties) reduces positive affect. Second, excessive negative affect is assumed to reduce the activation of extension memory and implicit self-representations
(Baumann \& Kuhl, 2002; Kazén, Baumann, \& Kuhl, 2003). Conversely, activation of extension memory and the self plays an important role in self-regulation of negative affect (Linville, 1987; Rothermund \& Meiniger, 2004; Showers \& Kling, 1996).

According to PSI theory, congruence between explicit and implicit motive measures is expected to occur when information can be exchanged between the two processing systems. More specifically, intention memory needs to "communicate" with extension memory in order to form valid representations of implicit needs in terms of self-congruent goals. An asymmetric activation of intention memory or, worse, an inhibition of extension memory is expected to disturb the communication process and reduce congruence between explicit orientations and implicit needs. Accordingly, chronic inhibition of positive affect (frustration) and/or chronic activation of negative affect (anxiety) are expected to disturb the communication process because of their modulatory influence on the cognitive systems. Chronic inhibition of positive affect is associated with an asymmetric activation of intention memory and consequently reduces the influence of extension memory in action control, for example, on explicit orientations (Kuhl \& Beckmann, 1994a). Chronic activation of negative affect is even worse for information exchange because it directly inhibits extension memory (Baumann \& Kuhl, 2002; Bolte, Goschke, \& Kuhl, 2003) and access to implicit needs. The finding that implicit and self-attributed motives are positively correlated only for individuals high in self-determination supports this assumption (Thrash \& Elliot, 2002) because, on a phenomenological level, self-inhibition should be experienced as low self-determination.

Congruence of personal strivings with organismic needs or implicit motives has been identified as an important predictor of emotional well-being, health, and personal growth (Brunstein et al., 1998; Sheldon \& Kasser, 1995). Because participants are often not aware of their unsatisfying orientation, motive incongruence can be conceived of as a hidden stress factor that partially mediates the direct relationship between unattenuated stress and reduced well-being. Because it is implausible to assume that incongruence between explicit and implicit motives is the sole reason that unattenuated stress affects well-being and symptom formation, partial rather than full mediation is expected (see Sapolsky, 1992, for evidence demonstrating direct routes from negative affect and stress to symptom formation).

\section{Stressful Life Events}

According to PSI theory, stressful life events can be differentiated into demands and threats. Life events that place high demands on a person (e.g., goal conflicts, high task difficulty, obstacles, and uncontrollability) are associated with reduced positive affect (Kuhl, 2001, p. 243) and activation of intention memory. Threatening life events (e.g., danger, major life changes, painful experiences, unpredictability, tasks that threaten self-worth) are associated with increased negative affect (Kuhl, 2001, p. 243) and inhibition of extension memory. However, stressful life events are expected to impair emotional well-being and balanced activation of cognitive systems only when a person is not able to cope with

\footnotetext{
${ }^{1}$ See Baumann and Kuhl (2002) for an experimental analysis of a task that capitalizes on a part of extension memory that is not related to the self.
} 
these events. Therefore, individual differences in coping (i.e., self-regulation of affect) are an important moderator.

\section{Affect Regulation}

The personality disposition of action versus state orientation captures individual differences in self-regulation under stress that are expected to moderate the influence of stressful life events on the activation dynamics of the two cognitive systems and, consequently, the ability to generate and implement motive-congruent goals. There are two major dimensions of action and state orientation (Kuhl, 1994a): First, decision-related action orientation (AOD) is the ability to self-generate positive affect in the face of difficulties and problems, that is, when it is necessary to implement self-congruent intentions (initiative). In contrast, decisionrelated state orientation (SOD, or hesitation) is associated with an inability to self-generate positive affect, which impairs implementation of self-congruent intentions (Beckmann \& Kuhl, 1984; Brunstein, 2001; Koole \& Jostmann, 2004). In this volitional vacuum, external requirements and social expectations can take over executive functions that are not supported by implicit selfrepresentations of one's own needs (Kuhl, 2000). Second, failurerelated action orientation (AOF) is the ability to reduce (downregulate) negative affect once it is aroused and to maintain access to integrated representations of one's own needs and implicit self-representations. AOF enables the individual to disengage from uncontrollable thoughts about negative events (disengagement). In contrast, failure-related state orientation ( $\mathrm{SOF}$, or preoccupation) is the inability to volitionally control negative affect and intrusive thoughts elicited by it. Perseverating negative affect presumably inhibits access to extension memory and implicit needs. During this state of self-inhibition, individuals lose access to their own emotional preferences (Guevara, 1994) and confuse others' goals and expectations with their own goals (Baumann \& Kuhl, 2003; Kuhl \& Kazén, 1994). Either component of state orientation may be accompanied by feelings of low self-determination (Thrash \& Elliot, 2002).

The conceptualization of state orientation in terms of a low ability to volitionally control affect is supported by many findings showing that deficits are observed only when the corresponding situational stressors are present (Kuhl \& Beckmann, 1994b), that is, demanding situations for hesitant participants (SOD) and threatening situations for preoccupied participants (SOF). These unfavorable combinations have been associated with such diverse phenomena as rumination, procrastination, alienation, depression, and anxiety (Kuhl, 2001; Kuhl \& Beckmann, 1994b). These findings demonstrate that the relationships between individual differences in affect regulation (i.e., action orientation) and subjectivewell being and symptom formation are well documented. Experimental studies have demonstrated that the relationship between action orientation and well-being is mediated by affectregulation abilities, that is, self-motivation (AOD) when confronted with demands and self-relaxation (AOF) when confronted with threats (Beckmann \& Kuhl, 1984; Koole \& Jostmann, 2004; Kuhl \& Baumann, 2000). A new research question in the present studies concerns the role of state and action orientation in motive incongruence. Brunstein (2001) found that state-oriented individuals are more likely to commit themselves to unrealistic and need-incongruent goals than are action-oriented individuals. Ac- cording to PSI theory, this personality difference is expected to occur only under stressful conditions.

\section{Hypotheses}

The mediational model tested in the present studies can be described as a series of separate hypotheses. First, the direct path predicts a Personality $\times$ Stress interaction on subjective wellbeing and symptoms. State-oriented participants were expected to show reduced subjective well-being (Studies 1 and 3) and increased symptoms (Study 2) as stressful life events increase. In contrast, action-oriented participants were not expected to be significantly influenced by stress. AOD was expected to moderate the effects of demands (Study 1), whereas AOF was expected to moderate the effects of threats (Studies 2 and 3).

Second, we predicted a Personality $\times$ Stress interaction on motive incongruence. State-oriented participants were expected to show greater incongruence between explicit achievement orientation and implicit achievement motive ( $n$ achievement) as stressful life events increased, whereas action-oriented participants were expected to retain motive congruence even under stress. This hypothesis is based on the assumption mentioned above that perseverating negative affect inhibits self-access, with the effect that implicit motives cannot easily be translated into the explicit format.

Third, motive incongruence can be conceived of as a hidden stressor expected to partially mediate the direct relationship between Personality $\times$ Stress and subjective well-being (Studies 1 and 3) and symptoms (Study 2). We did not expect full mediation because chronic need frustration is only one way in which stressful life events may influence well-being and the concentration of the stress hormone cortisol that has been associated with a diversity of symptoms (Sapolsky, 1992). Other aspects of the situation (e.g., time pressure, goal conflicts, painful experiences) may be experienced as stressful even when individuals are oriented toward satisfying goals. However, these stress factors were expected to be less crucial. For example, Sheldon and Kasser (1995) found that goal conflicts do not impair well-being as long as goals are oriented toward satisfying basic needs.

In addition, the studies were designed to compare similarities and differences in the determinants of subjective well-being in symptom-free individuals (Studies 1 and 3 ) and symptom formation in a clinical sample (Study 2). In the latter sample, the focus was on a common determinant of symptom formation (i.e., motive incongruence) that affects a variety of psychological symptoms. Whereas Studies 1 and 2 are correlational, Study 3 examines the causal role of stress in the development of motive incongruence by experimentally manipulating the level of stress (threat vs. acceptance).

\section{Study 1}

Confrontation with high demands and the resulting chronic activation of intention memory for hesitant participants (who are not able to self-generate positive affect) are conditions that are expected to occur in healthy populations and influence subjective well-being partially as a result of motive-incongruent achievement orientations. Therefore, a nonpatient sample was tested in Study 1. 


\section{Method}

\section{Participants}

Sixty-two participants ( 30 women and 32 men) were recruited through flyers around the university of Osnabrück offering individual counseling on personality development. Participants were given detailed feedback on their individual scores in return for their participation. Their mean age was 32.7 years (range $=14$ to 57 years).

\section{Materials}

The Action Control Scale (ACS-90; Kuhl, 1994b) was administered. It consists of 24 items. The following is an example item on the decisionrelated dimension: "When I know I must finish something soon: (a) I have to push myself to get started, or (b) I find it easy to get it done and over with." Option "a" reflects the SOD and Option "b" represents the AOD response alternative. An example item on the failure-related dimension follows: "When I am told that my work has been completely unsatisfactory: (a) I don't let it bother me for too long, or (b) I feel paralyzed." Option "a" reflects the AOF and Option b, the SOF response alternative. The ACS has sufficient reliability (Cronbach's alphas $>.70$ ) and adequate construct validity (Kuhl \& Beckmann, 1994b). The factorial structure of the ACS-90 confirms the theoretical distinction made between the AOD and AOF components of action orientation (Dieffendorf, Hall, Lord, \& Strean, 2000; Kuhl \& Beckmann, 1994b). In the present study, AOD and AOF scales had internal consistencies (Cronbach's alpha) of $\alpha=.80$ and $\alpha=.71$, respectively.

A life stress scale was administered, with the two subscales (demands and threats) consisting of 10 items each. Example items on the Demands scale include the following: "I experience many conflicts between incompatible goals in my life"; "My current life circumstances are very tough"; and "I must cope with a lot of difficulties." The following are example items on the Threats scale: "I must deal with big changes in my life"; "I have many painful experiences to cope with"; "I have felt a lot of conflict and hostility between myself and others lately." These two types of stressors load on orthogonal factors and show the theoretically expected correlations with affect (cf. Kuhl, 2001, p. 243). In a student sample, the Demand scale was significantly correlated with the number of critical life events during the previous 2 weeks $(r=.59, p<.01)$ and with total stress scores $(r=.62, p<.01)$ in the College Undergraduate Stress Scale (Renner \& Mackin, 1998). Correlations between threats and the number of critical life events $(r=.25, p<.09)$ and total stress scores $(r=.27, p<$ .07) were only marginally significant. The lower relationships for the Threat scale may indicate (a) that the College Undergraduate Stress Scale covers more demanding events than threatening ones and/or (b) that students are typically confronted with demands more often than threats. Consistent with both assumptions, participants rated their life events as significantly more demanding $(M=1.31, S D=0.62)$ than threatening $(M=1.05, S D=0.65)$, $t(47)=4.76, p<.01$. The findings reported above contribute to the validity of our self-report measures of stress. In the present sample, internal consistencies were $\alpha=.88$ for demands and $\alpha=.89$ for threats.

Explicit achievement orientation was assessed by four items selected from the Motive Enactment Test (Motiv-Umsetzungs-Test, MUT; Kuhl, 1999; Kuhl \& Henseler, 2003): (a) "When I have solved a difficult problem I enjoy looking for the next challenge right away"; (b) "When there is a difficult task to do I often volunteer"; (c) "When I can work for hours on a difficult project, I am completely happy"; (d) "I often engage spontaneously in activities in which I can test my abilities." In a representative sample of 155 participants, the achievement orientation scale had an internal consistency of $\alpha=.82$ (Kuhl, 1999). In the present sample, internal consistency was lower $(\alpha=.64)$ but still sufficient.

The Operant Multimotive Test (OMT; Kuhl \& Scheffer, 1999) was administered to assess the implicit achievement motive ( $n$ achievement). Using a modified TAT technique, we presented participants with 15 pictures and asked them to invent a story (without having to write down the story) and give their spontaneous associations to the following questions: (a) "What is important for the person in this situation and what is the person doing?" (b) "How does the person feel?" (c) "Why does the person feel this way?" and (d) "How does the story end?" The OMT differentiates four approach components for each motive by crossing two affective sources of motivation (positive vs. negative) with self-determined versus incentive-focused forms of motivation. For the achievement motive, the two positive modes of approach motivation can be described as self-determined flow (learning something, being absorbed, concentrated) and standard of excellence (doing something well, being proud, focused on results), whereas the two motivational modes driven by negative affect consist of self-determined coping with failure (perception of threat associated with active coping) and pressure to achieve (social standards, relief after success). ${ }^{2}$ In addition, the OMT contains a passive avoidance component for each motive (e.g., fear of failure). The differentiation of five forms of motivation allowed us to test theoretically interesting differences in the type of self-regulation involved in need-satisfaction. For the purpose of the present studies, the sum of the four approach components of the achievement motive was computed to assess the implicit achievement motive ( $n$ achievement). The passive avoidance component was omitted because the explicit items also tap approach. Extensive research on the OMT has been reported in Scheffer (2005). The total OMT achievement score is significantly correlated with TAT achievement scores coded according to Winter (1991), $r=.64, p<.05$, supporting the convergent validity of the measure. Behavioral correlates further support the validity of the operant motive test. For example, adolescents high in $n$ achievement were significantly more efficient in applying for an apprenticeship than adolescents low in $n$ achievement because their aspired positions matched their level of qualification (Heckhausen \& Tomasik, 2002). New for an operant motive measure is the finding of sufficient internal consistency, even according to indices based on classical test theory, $\alpha=.70$, and sufficient retest stability of $r=.72$ (Scheffer, Kuhl, \& Eichstaedt, 2003). Scoring was carried out by well-trained assistants who had attained sufficient reliability across several studies.

Subjective well-being was assessed by 16 items. Example items included the following: "Emotionally I feel just fine at the moment"; "I feel very productive at the moment"; "During the last days I felt relaxed"; and "I have difficulties coordinating job and private life" (reversed). In the present sample, internal consistency was $\alpha=.92$.

\section{Procedure}

Participants received the questionnaire packets (OMT, MUT, ACS-90, life stress, subjective well-being) at the university of Osnabrück and were asked to return the completed questionnaires within the next few days. The whole packet took about $60 \mathrm{~min}$ to complete. The personality assessment was the basis for counseling on opportunities for personality development, provided as compensation for participation. Counseling sessions were held individually and lasted about $30 \mathrm{~min}$.

\section{Results}

\section{Correlations}

To demonstrate discriminative validity of our measures, we calculated correlations (see Table 1, values above the diagonal). Achievement orientation was expected to assess something different from a successful active coping style, as tapped in the ACS-90.

\footnotetext{
${ }^{2}$ In case of motive congruence, the four components of the OMT might correspond to the four goal types described in Elliot's (1997) hierarchical model: (a) Flow might correspond to mastery-approach goals, (b) standard of excellence might correspond to performance-approach goals, (c) coping with failure might correspond to mastery-avoidance, and (d) pressure to achieve might correspond to performance-avoidance.
} 
Table 1

Bivariate Correlations of Variables in Study 1 and Study 2

\begin{tabular}{|c|c|c|c|c|c|c|c|}
\hline Variable & AOF & AOD & Threats & Demands & $n$ Ach & Ach Or & SWB \\
\hline $\mathrm{AOF}$ & & $.38 * *$ & $-.47 * *$ & $-.48 * *$ & .24 & .09 & $.49 * *$ \\
\hline AOD & $.60 * *$ & & $-.36^{* * *}$ & $-.45 * *$ & .21 & $.30 *$ & $.53 * *$ \\
\hline Threats & -.19 & -.16 & & $.88 * *$ & -.16 & .16 & $-.74 * *$ \\
\hline Demands & $-.39 *$ & $-.39 *$ & $.73 * *$ & & -.18 & .01 & $-.68 * *$ \\
\hline$n$ Ach & .22 & .14 & .08 & .09 & & .17 & -.08 \\
\hline Ach Or & $.38 *$ & $.45^{* *}$ & .11 & .08 & .22 & & -.19 \\
\hline Symptoms at $\mathrm{T} 1$ & -.30 & -.22 & $.27 *$ & $.39 *$ & .06 & .08 & \\
\hline Symptoms at $\mathrm{T} 2$ & $-.45 * *$ & -.28 & .11 & $.35 *$ & .06 & -.12 & $.35^{\mathrm{a} *}$ \\
\hline
\end{tabular}

Note. Correlations for study $1(n=42)$ are presented above the diagonal, and correlations for study $2(N=62)$ are presented below the diagonal. AOF $=$ failure-related action orientation; $\mathrm{AOD}=$ decision-related action orientation; $n$ Ach $=$ implicit achievement motive; Ach Or $=$ explicit achievement orientation; SWB = subjective well-being in Study 1.

${ }^{a}$ Correlation between symptoms at $\mathrm{T} 1$ and symptoms at $\mathrm{T} 2$ in Study 2.

Consistent with expectations, achievement orientation and AOD showed a significant but only moderate correlation $(r=.30, p<.02)$. More important, only AOD showed a significant correlation with subjective well-being $(r=.53, p<.001)$, whereas achievement orientation did not significantly correlate with subjective well-being $(r=-.19, p<.15)$. These findings support the hypothesized relationship between AOD and affect regulation and demonstrate the discriminative validity of achievement orientation and AOD.

\section{Affect Regulation and Subjective Well-Being}

A hierarchical regression analysis was conducted on subjective well-being, with AOD and demands entered as the first block, and their interaction term entered as the second. Following a recommendation by Aiken and West (1991), in all analyses, predictor variables were standardized before their interaction term was calculated. There were significant main effects of AOD, $\beta=.29, t(59)=2.83, p<.01$, and Demands, $\beta=-.55, t(59)=-5.46, p<.01$. More important, there was a significant AOD $\times$ Demands interaction, $\beta=.20, t(58)=$ 2.32, $p<.03$. Unstandardized regression weights conducted with a range of $\pm 1 S D$ for both predictor variables were used to graph this interaction effect. The relation between demands and subjective wellbeing varied as a function of state and action orientation, as predicted. Consistent with expectations, state-oriented participants showed substantially lower subjective well-being as demands increased: for low demands, $M=0.53$ and for high demands, $M=-0.92, t(58)=$ $-5.88, p<.01$. Action-oriented participants showed the same tendency: for low demands, $M=0.69$ and for high demands, $M=0.06$, $58)=-2.23, p<.03$. However, they were less influenced in their subjective well-being by demands. Simple slope analyses (O'Connor, 1998) yielded a significant difference between state- and actionoriented participants experiencing high demands, $t(58)=3.73, p<$ .01 . Findings support the hypothesis that the influence of demands on subjective well-being was moderated by decision-related state and action orientation. An additional regression analysis was conducted on subjective well-being, including AOF, threats, and their interaction term. The AOF $\times$ Threats interaction was marginally significant, $\beta=$ $.17, t(58)=1.84, p<.08$. Furthermore, the cross interactions AOD $\times$ Threats, $\beta=.08, t(58)=1.00, p<.32$, and AOF $\times$ Demands, $\beta=.11, t(58)=1.08, p<.29$, were not significant.

\section{Affect Regulation and Motive-Incongruent Achievement Orientation}

The amount of motive-incongruent achievement orientation was calculated as the absolute difference between standardized explicit achievement orientation and standardized implicit achievement motives ( $n$ achievement), where higher scores indicate higher incongruence. A hierarchical regression analysis was conducted on motive incongruence with AOD and demands entered as the first block, and their interaction term entered as the second block. There was a significant $\mathrm{AOD} \times$ Demands interaction for achievement motive incongruence, $\beta=-.25, t(58)=-2.10, p<.05$. Unstandardized regression weights with a range of $\pm 1 S D$ for both predictor variables were used to graph this interaction effect. Figure 1 shows that the relationship between demands and incongruence between achievement orientation and $n$ achievement varied as a function of state and action orientation. Consistent with expectations, state-oriented participants showed significantly greater incongruence between achievement orientation and $n$ achievement as demands increased, $t(58)=$ $2.69, p<.01$, whereas action-oriented participants retained congruence as demands increased, $t(58)=-0.30, p<.77$. No other effects were significant. An additional regression analysis was conducted on achievement motive congruence, including AOF, threats, and their interaction term. The AOF $\times$ Threats interaction was not significant, $\beta=-.05, t(58)=-0.38, p<.77$. Furthermore, the cross interactions AOD $\times$ Threats, $\beta=-.12, t(58)=-0.92, p<.37$, and $\mathrm{AOF} \times$ Demands, $\beta=-.07, t(58)=-0.48, p<.64$, were not significant. Findings provided support for the hypothesis that the influence of life stress on formation of motive-incongruent orientations was moderated by state and action orientation. More specifically, the influence of demands on motive-incongruent achievement orientations was moderated by decision-related state and action orientation.

\section{Motive-Incongruent Achievement Orientation and Subjective Well-Being}

A hierarchical regression analysis was conducted on subjective well-being, with achievement orientation and $n$ achievement entered as the first block and their interaction term entered as the second block. There was a significant $n$ Achievement $\times$ Achievement Ori- 


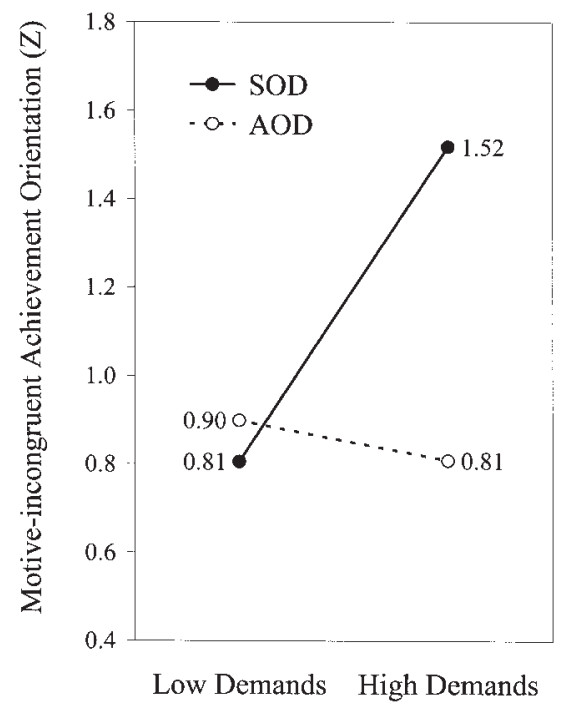

Figure 1. Incongruence (absolute difference) between implicit achievement motive and explicit achievement orientation as a function of perceived life stress (i.e., demands) and decision-related state orientation (SOD) and action orientation (AOD) in Study 1. Low and high values on demands as well as low (SOD) and high (AOD) values on decision-related action orientation correspond to one standard deviation below and above the mean, respectively.

entation interaction, $\beta=.20, t(58)=2.32, p<.03$. Unstandardized regression weights with a range of $\pm 1 S D$ for both predictor variables were used to graph this interaction effect. Figure 2 shows that congruence between $n$ achievement and achievement orientation was associated with subjective well-being. In contrast, placing great importance on achievement despite low $n$ achievement scores as well as placing low importance on achievement despite high $n$ achievement scores was associated with low subjective well-being. Consistent with our hypothesis, both types of incongruence were detrimental to subjective well-being. Simple slope analyses were significant for low $n$ achievement, $t(58)=-3.19, p<.01$, and marginally significant for high $n$ achievement, $t(58)=1.85, p<.07$. In an independent $t$ test, the group of 10 participants overestimating their $n$ achievement scores by at least $1 S D$ was not significantly different in their subjective well-being from the group of 13 participants underestimating their $n$ achievement scores by at least $1 S D, M=-0.69$ vs. $M=-0.42$, $t(21)=-0.62, p<.54$. In contrast, the congruent group had significantly higher subjective well-being $(M=0.32)$ than overestimators, $t(47)=3.02, p<.01$, as well as underestimators, $t(50)=2.76, p<.01$.

\section{Mediational Model}

The direct effect of the AOD $\times$ Demands interaction on subjective well-being was expected to be partially mediated by motive-incongruent achievement orientations. To test the mediational model, we conducted a series of separate path analyses (Baron \& Kenny, 1986). First, AOD $\times$ Demands directly affected subjective well-being (see above). Second, AOD $\times$ Demands was predictive of the amount of motive-incongruent achievement orientation (see Figure 1). Third, when AOD $\times$ Demands and amount of motive-incongruent achievement orientation were entered into the equation simultaneously (controlling for main effects of AOD and demands), motive-incongruent achievement orientation was predictive of subjective well-being, $\beta=-.21, t(57)=-2.19, p<$ .05. Moreover, the direct relationship between AOD $\times$ Demands and subjective well-being was no longer significant, $\beta=.15$, $t(57)=1.73, p<.09$. The mediational model is illustrated in Figure 3. Findings are consistent with the assumption that individuals high in decision-related state orientation (i.e., low AOD scores) are prone to show motive-incongruent achievement orientations when experiencing high demands. These motiveincongruent orientations are one of the reasons why state-oriented individuals under high demands show less subjective well-being. ${ }^{3}$

Alternative model. An alternative hypothesis is that motive incongruence interacts with stress to predict well-being, mediated by state orientation. In other words, individuals with motiveincongruent achievement orientations may not be able to respond adequately to stress and become state-oriented. The state-oriented response may mediate the direct relationship between the direct effect of incongruence and stress on well-being. To test this alternative model, a series of separate path analyses was conducted. First, the Motive Incongruence $\times$ Demands interaction on subjective well-being (controlling for main effects) was not significant, $\beta=-.25, t(58)=-1.49, p<.15$. Second, the Motive Incongruence $\times$ Demands interaction on AOD (controlling for main effects) was not significant, $\beta=-.18, t(58)=-0.82, p<$ .42 . Thus, results do not support the alternative model. Motive incongruence seems to be a hidden stress factor itself that does not depend on the presence of demanding life-events to exert a detrimental influence on subjective well-being, Furthermore, the combination of motive incongruence and high demands was not associated with a state-oriented coping style. Presumably, state versus action orientation is a rather stable disposition that determines how individuals cope under stress and not how much stress they experience.

\footnotetext{
${ }^{3}$ As an alternative operationalization of motive congruence, the product between standardized achievement orientations and standardized $n$ achievement was calculated, with higher scores indicating higher congruence. The mediational model yielded the same significant results: First, AOD $\times$ Demands directly affected subjective well-being (see above). Second, AOD $\times$ Demands was predictive of the amount of motive congruence, $\beta=.28, t(58)=2.28, p<.05$. Third, when AOD $\times$ Demands and motive congruence were entered into the equation simultaneously (controlling for main effects), motive congruence was predictive of subjective well-being, $\beta=.23, t(57)=2.54, p<.02$. Moreover, the direct relationship between AOD $\times$ Demands and subjective well-being was no longer significant, $\beta=.14, t(57)=1.60, p<.12$. An advantage of the product measure was that in the third path, this operationalization is more informative because it does not confound discrepancy per se with the original variables that were used to compute the discrepancy score (i.e., implicit and explicit motive scores). A disadvantage of the product measure is that in the second path, the Implicit $\times$ Explicit product term is mixed with main effects. It is not clear whether AOD $\times$ Demands is predicting congruence, simply higher levels of the motive variables, or some mixture of these. Because the two types of motive discrepancies (underestimators and overestimators) did not show meaningful differences in our study (see above), we preferred the use of absolute difference scores.
} 


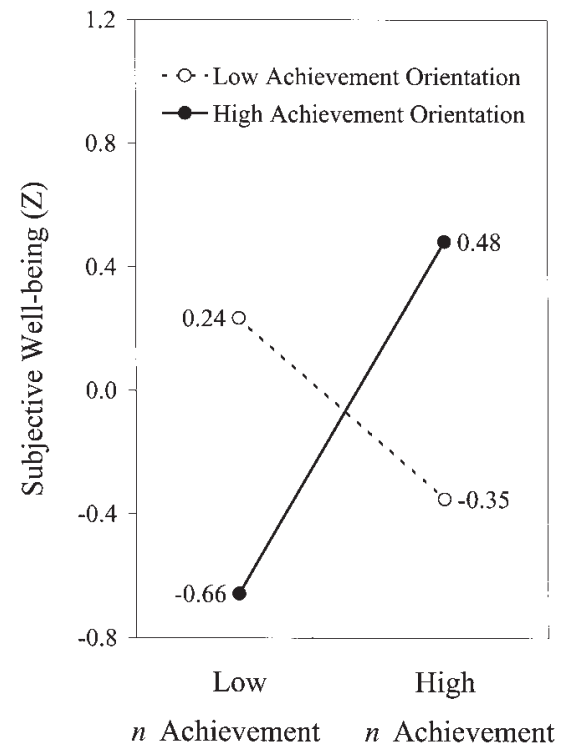

Figure 2. Subjective well-being as a function of implicit achievement motive and explicit achievement orientation in Study 1. Low and high values correspond to one standard deviation below and above the mean, respectively. $n$ Ach $=$ implicit achievement motivation.

\section{Discussion}

Study 1 was designed to test motive-incongruent achievement orientations as a hidden stressor that mediates subjective wellbeing in a healthy population. The results of Study 1 support the mediational model: Motive-incongruent achievement orientations partially mediate the direct effect of a combination of low volitional control of positive affect (SOD) and excessive demands in everyday life on subjective well-being. We discuss the several paths in this model in more detail. It is a new finding that a combination of SOD and demanding life events fosters a cognitive imbalance between memory systems representing explicit intentions and implicit motives so that achievement orientations are less self-congruent. Until now, decision-related state orientation has been confined to correlates of behavioral or volitional inhibition such as manifest alienation, that is, an inability to act on emotional preferences (Guevara, 1994; Kuhl \& Beckmann, 1994a), procrastination (Beswick \& Mann, 1994; Fuhrmann \& Kuhl, 1998), and informed introjection, that is, a tendency to act according to what other persons expect one to do (Kuhl \& Kazén, 1994). As mentioned in the introductory section, an explanation of the findings related to behavioral facilitation can be directly derived from the assumption that decision-related action orientation indicates the ability to generate positive affect (Beckmann \& Kuhl, 1984) that is needed for behavioral facilitation (Gray, 1987). Recent findings (Koole \& Jostmann, 2004) not only demonstrate that actionoriented individuals are characterized by the ability to generate positive affect in difficult (demanding) situations but that the mechanism underlying this ability operates on a subconscious level involving self-access as postulated by PSI theory (Kuhl, 2000, 2001, chap. 14).

How can the relationship between SOD, situational demands, and motive incongruence be explained? According to PSI theory, a difficult or demanding situation dampens positive affect unless this effect is counterregulated by a self-regulatory mechanism (i.e., self-motivation). To the extent that this mechanism is impaired in prospectively state-oriented individuals, the inhibition of positive affect perseverates and activates explicit representations of uncompleted actions in intention memory: According to previous findings, SOD is, in fact, associated with an overmaintenance of explicit intentions (Goschke \& Kuhl, 1993) that seems to impair enactment of difficult intentions (Kuhl \& Helle, 1986) because maintenance of explicit intentions entails an inhibitory component (Kuhl \& Kazén, 1999). Because of the antagonism between intention and extension memory postulated in PSI theory, prolonged activation of explicit intentions should be negatively related to activation of implicit representations of needs and motives. Thus, the described mechanism may contribute to both types of motive incongruence: (a) the maintenance of orientations that are not supported by implicit motives and (b) a failure to activate orientations that are supported by implicit motives. The observed relationship between SOD, demands, and motive incongruence confirms this theoretical argument (see Figure 1).

The present findings support the assumption that motiveincongruent achievement orientations are associated with less subjective well-being (see Figure 2). This finding is quite plausible: In the story presented at the beginning of this article, it is not hard to imagine how unhappy the two men would be if they had to switch roles. In addition, the finding is consistent with previous research in which positive relationships between motive congruence and well-being have been obtained with traditional TAT measures (Brunstein et al., 1998; Hofer \& Chasiotis, 2003). The present study replicates these findings with a new operant motive test (OMT). A new finding in the present study is that motive-incongruent achievement orientations partially mediate the direct relationship between unfavorable conditions (SOD and demands) and reduced subjective well-being. The mediation is only partial because unattenuated stress may influence subjective well-being in many different ways. The present data suggest that chronic need frustration is one important mechanism that can explain much of the variance: Individuals with an inability to access implicit motives under stress cannot satisfy basic needs and feel ill. An alternative model, that motive incongruence interacts with stress to predict well-being and that this direct effect is mediated by action orientation was not supported by the data. Outer stress factors (demands) did not add to the detrimental influence of the

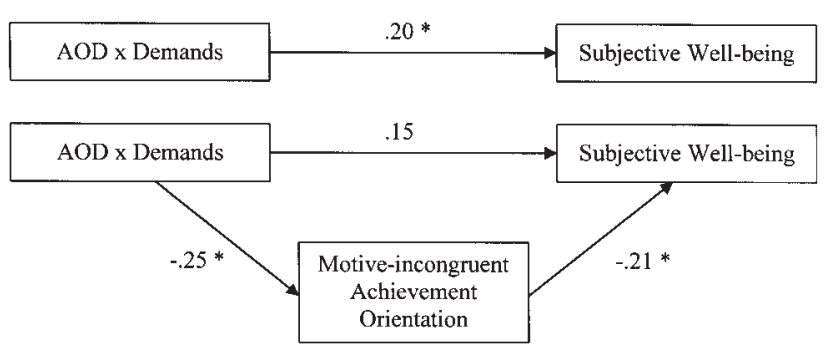

Figure 3. The mediational model with motive-incongruent achievement orientation as partially mediating the direct effect of perceived life stress (i.e., demands) and decision-related action orientation (AOD) on subjective well-being in Study 1. Coefficients are standardized betas. $* p<.05$. 
inner stress factor (motive incongruence). Furthermore, the combination of inner and outer stress factors did not predict self-regulatory abilities. State versus action orientation is conceived of as a rather stable disposition. The prospective design of Study 2 allowed us to further test this assumption.

To summarize, the present findings point to the importance of assessing underlying implicit motives in order to evaluate the self-congruence of explicit achievement orientations. Study 2 intended to explore similarities and differences in the determinants of impaired psychological well-being as exemplified by psychological symptoms of patients undergoing psychotherapy or rehabilitation.

\section{Study 2}

Psychological symptoms such as anxiety, depression, and obsessive-compulsive disorders are closely related to emotional problems, which often result in psychosomatic complaints. According to PSI theory, coping with difficult emotions depends on self-regulatory functions that differ from those relevant for goal enactment. As a result, action versus state orientation after failure (AOF vs. SOF) and the amount of threatening life experiences should be more relevant for the relationship between motive incongruence and symptom formation than the relation between decision-related action orientation and situational demands. The implicit self and the processing system supporting it (i.e., extension memory) is conceived of as a semantic network that integrates implicit knowledge and emotional experiences from autobiographical memory (Damasio, Tranel \& Damasio, 1991; Greenwald \& Banaji, 1995; Wheeler, Stuss \& Tulving, 1997). The ability to cope with stress and negative emotionality and to prevent stressdependent symptoms critically depends on the degree of differentiation of the self (Linville, 1987; Rothermund \& Meiniger, 2004; Showers \& Kling, 1996).

According to PSI theory, the experience of threat and a dispositional deficit in self-regulation of negative affect are expected to inhibit extension memory and self-access. State-oriented (SOF) individuals' perseverating preoccupation after failure or after other stressful experiences illustrates the impaired ability to downregulate negative affect (Kuhl \& Baumann, 2000). State-oriented individuals' impaired self-access has been demonstrated in terms of latent alienation (i.e., impaired perception of one's emotional preferences) as operationalized by inconsistent preference judgments and near-zero regression coefficients of decision times as a function of valence differences among alternatives (Guevara, 1994; Kuhl \& Beckmann, 1994a). Another indication of impaired self-access associated with failure-related state-orientation is misinformed introjection, or self-infiltration, which is operationalized by a tendency to misperceive others' expectations as one's own goals (Baumann \& Kuhl, 2003; Kuhl \& Kazén, 1994).

In clinical patients, self-inhibition is expected to be a more critical antecedent of incongruence between explicit orientations and implicit motives than activation of intention memory because of the crucial role self-access plays in coping with negative affect, stress, and stress-dependent symptoms. In contrast to an impaired ability to implement emotional preferences or cognitive intentions, impaired self-access amounts to a difficulty in perceiving one's emotional preferences and controlling one's emotional responses, especially painful and threatening emotions. In the story presented at the beginning of this article, imagine the two men starting to believe that they truly want to switch roles: On a conscious level, they would assume self-congruence of their new role although their implicit motive structure would not have changed. This more severe type of imbalance between cognitive systems was expected to occur with patients and to predict motive-incongruent achievement orientations. Furthermore, motive-incongruent achievement orientations were expected to mediate the course of emotional and somatic problems among patients over a period of 3 months.

\section{Method}

\section{Participants}

Forty-two patients (18 women and 24 men) were recruited from two psychosomatic and rehabilitation clinics and two private psychiatric practices. Their mean age was 44.4 years (range $=25$ to 71 years). Thirteen patients were in treatment for skin diseases (neurodermatitis, psoriasis, urticaria), 6 patients for chronic alcohol abuse, and 1 patient for chronic lower back pain. The following diagnoses (including multiple classifications for comorbidity) identified in the 10th revision of the International Classification of Diseases (ICD-10) were obtained for the remaining 22 patients (World Health Organization, 1992): 10 classifications of affective disorders, 14 neurotic, stress, and somatoform disorders; 11 personality and behavioral disorders; 1 organic amnestic syndrome; 1 bulimia nervosa, and 1 hyperactive disorder. This heterogeneous patient sample was considered appropriate for Study 2 because the central hypothesis relates to a nonspecific determinant of mental illness.

A subsample of 23 patients (11 women and 12 men) completed additional questionnaires at a 3-month follow-up (see Procedure section). Their mean age was 43.8 years (range $=29$ to 71 years). In this subsample, the distribution of disorders was similar to the one described above for the total sample. There was no symptom- or gender-specific dropout.

\section{Materials}

As in Study 1, the OMT, the MUT, the ACS-90, and life stress scales were assessed. In the present sample, internal consistencies (Cronbach's alpha) were $\alpha=.81$ for AOF, $\alpha=.85$ for AOD, $\alpha=.79$ for threats, $\alpha=$ .65 for demands, and $\alpha=.69$ for explicit achievement orientations. Instead of subjective well-being, emotional and somatic complaints were assessed at the beginning of the study (T1) and at a 3-month follow-up (T2). The scale consists of 16 items. Example items include the following: "During the last days I suffered from my emotional problems and symptoms"; “. . . I suffered from somatic complaints (e.g., head-ache, stomach-ache, backpain etc.)"; ". . .I had problems sleeping”; “. . . I had intrusive, uncontrollable thoughts"; ". . . I felt anxious”; and ". . . I felt helpless.” In the present sample, the scale for emotional and somatic complaints had an internal consistency of $\alpha=.92$.

\section{Procedure}

Questionnaire packets were filled out as part of a standard anamnesis (pretreatment assessment). All participants filled out the OMT, the MUT, the ACS-90, life stress scales, and a symptom checklist at the beginning of their treatment (T1). The 3-month follow-up was part of a standard catamnesis (posttreatment assessment). All participants filled out the symptom checklist at the end of their treatment (T2). A subsample of 23 participants was willing to also complete the OMT, MUT, ACS-90, and life stress scales at $\mathrm{T} 2$.

\section{Results}

\section{Correlations}

To demonstrate discriminative validity of our measures, we calculated correlations (see values below the diagonal in Table 1). 
Despite a moderate correlation between achievement orientation and AOF $(r=.38, p<.05)$, only AOF showed a significant negative correlation with symptoms at T2 $(r=-.45, p<.01)$, whereas achievement orientation did not significantly correlate with symptoms at T2 $(r=.12, p<.44)$. Findings supported the hypothesized relationship between $\mathrm{AOF}$ and symptom formation and demonstrated the discriminative validity of achievement orientation and $\mathrm{AOF}$.

\section{Affect Regulation and Changes in Symptom Formation}

Hierarchical regression analyses were conducted on changes in symptoms over a period of 3 months. Somatic complaints at T2 were regressed on somatic complaints at $\mathrm{T} 1$ and entered as the first block, AOF and threats were entered as the second block, and the interaction term was entered as the third block. There was a significant $\mathrm{AOF} \times$ Threats interaction, $\beta=-.31, t(37)=-2.47$, $p<.02$. Unstandardized regression weights with a range of \pm 1 $S D$ for both predictor variables were used to graph this interaction effect. The relation between threats and symptom formation after 3 months varied as a function of state and action orientation. Consistent with expectations, state-oriented participants showed significantly higher somatic complaints as threats increased: for low threats, $M=-0.10$ and for high threats, $M=0.56$; $t(38)=$ 2.60, $p<.02$. In contrast, action-oriented participants had a nonsignificant tendency toward lower somatic complaints as threats increased: for low threats, $M=-.05$ and for high threats: $M=-0.57, t(38)=-0.75, n s$. Simple slope analyses yielded a significant difference between state- and action-oriented participants experiencing high threats, $t(38)=-3.44, p<.01$. Findings provided support for the hypothesis that the influence of threats on symptom formation after 3 months was moderated by failurerelated state and action orientation. An analogous regression analysis was conducted on somatic complaints at T2 (controlling for T1), including AOD, demands, and their interaction term. The AOD $\times$ Demands interaction was not significant, $\beta=-.10$, $t(37)=-0.69, p<.50$. Furthermore, the cross-interactions AOF $\times$ Demands, $\beta=-.26, t(37)=-1.13, p<.28$, and AOD $\times$ Threats, $\beta=-.02, t(37)=-0.11, p<.92$, were not significant.

\section{Affect Regulation and Motive-Incongruent Achievement Orientation}

A hierarchical regression analysis was conducted on motive incongruence (i.e., absolute difference between standardized $n$ achievement and standardized achievement orientation), with AOF and threats entered as the first block and their interaction term entered as the second block. There was a significant AOF $\times$ Threats interaction for achievement motive incongruence, $\beta=$ $-.32, t(38)=-2.22, p<.05$. Unstandardized regression weights with a range of $\pm 1 S D$ for both predictor variables were used to graph this interaction effect. As illustrated in Figure 4, the relation between threats and motive incongruence varied as a function of state and action orientation, as predicted. State-oriented participants showed significantly higher incongruence between $n$ achievement and achievement orientation as threats increased, $t(38)=2.53, p<.02$, whereas action-oriented participants were not significantly influenced by threats, $t(38)=-0.28, p<.79$. No other effects were significant. An additional regression analysis

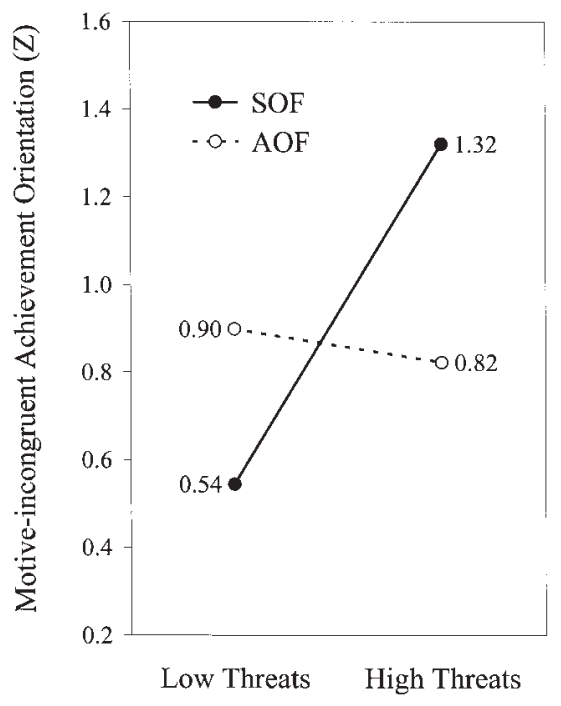

Figure 4. Incongruence (absolute difference) between implicit achievement motive and explicit achievement orientation as a function of perceived life stress (i.e., threats) and failure-related state orientation (SOF) and action orientation (AOF) in Study 2. Low and high values on threats as well as low (SOF) and high (AOF) values on failure-related action orientation correspond to one standard deviation below and above the mean, respectively.

was conducted on achievement motive incongruence, including AOD, demands, and their interaction term. The AOD $\times$ Demands interaction was not significant, $\beta=.02, t(38)=0.16, p<.88$. Furthermore, the cross interactions AOF $\times$ Demands, $\beta=-.27$, $t(38)=-1.68, p<.11$, and AOD $\times$ Threats, $\beta=.07, t(38)=$ $0.50, p<.62$, were not significant. Regression analyses provided support for the hypothesis that the influence of life stress on formation of motive-incongruent orientations was moderated by state and action orientation. More specifically, the influence of threats on motive-incongruent achievement orientation was moderated by failure-related state and action orientation.

\section{Motive-Incongruent Achievement Orientation and Changes in Symptom Formation}

A hierarchical regression analysis was conducted on symptoms at T2 (controlling for T1), with achievement orientation and $n$ achievement entered as the first block and their interaction term entered as the second block. There was a significant $n$ Achievement $\times$ Achievement Orientation interaction, $\beta=.20, t(58)=$ 2.32, $p<.03$. Unstandardized regression weights with a range of $\pm 1 S D$ for both predictor variables were used to graph this interaction effect. Figure 5 shows that congruence between $n$ achievement and achievement orientation was associated with low symptoms at T2. In contrast, placing great importance on achievement despite low $n$ achievement scores as well as placing low importance on achievement despite high $n$ achievement scores was associated with high symptoms after a period of 3 months. Consistent with our hypothesis, both types of incongruence were detrimental to treatment success. Simple slope analyses were marginally significant for low levels of $n$ achievement, $t(38)=1.94$, $p<.06$, and were also significant for high $n$ achievement, $t(38)=$ 


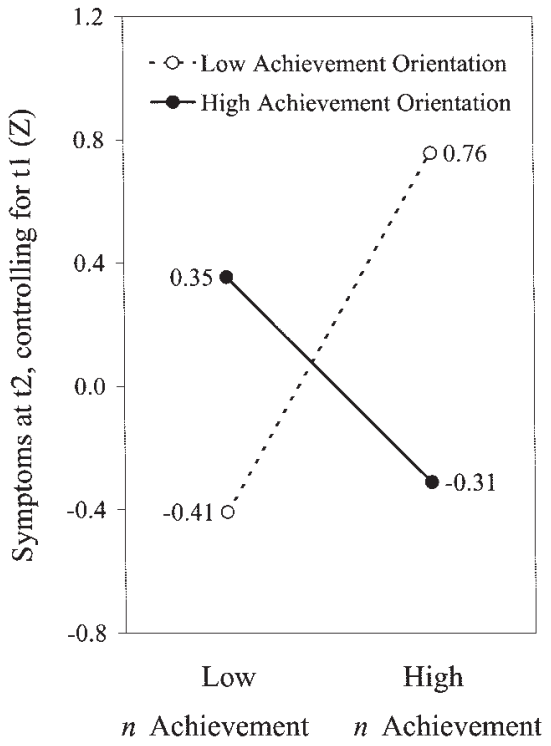

Figure 5. Symptoms after three months (Time 2), controlling for symptoms at Time 1, as a function of implicit achievement motive and explicit achievement orientation in Study 2. Low and high values on threats as well as low and high failure-related state orientation values on failure-related action orientation correspond to one standard deviation below and above the mean, respectively. $n$ Achievement $=$ implicit achievement motivation.

$-3.25, p<.01$. In an independent $t$ test, the group of 9 participants overestimating their $n$ achievement scores by at least $1 S D$ was not significantly different in symptom severity from the group of 9 participants underestimating their $n$ achievement scores by at least $1 S D, M=0.50$ vs. $M=0.37, t(16)=0.32, p<.76$. In contrast, the congruent group had lower symptoms $(M=-0.33)$ than overestimators, $t(31)=-2.21, p<.05$, and underestimators, $t(31)=-1.83, p<.08$.

\section{Mediational Model}

The direct effect of the AOF $\times$ Threats interaction on changes in symptom formation over a period of 3 months was expected to be partially mediated by motive-incongruent achievement orientations. To test the mediational model, a series of separate path analyses was completed. First, AOF $\times$ Threats directly affected changes in symptoms over a period of 3 months (see above). Second, AOF $\times$ Threats was predictive of the amount of motiveincongruent achievement orientation (see Figure 4). Third, when AOF $\times$ Threats (controlling for main effects of AOF and threats) and amount of motive-incongruent achievement orientation were entered into the equation simultaneously, motive-incongruent achievement orientations were predictive of somatic complaints at $\mathrm{T} 2$ (controlling for somatic complaints at T1), $\beta=.27, t(36)=$ 2.04, $p<.05$. Moreover, the direct relationship between AOF $\times$ Threats and somatic complaints was no longer significant, $\beta=$ $-.23, t(36)=-1.77, p<.09$. The mediational model is illustrated in Figure 6. Findings are consistent with the assumption that individuals high in failure-related state orientation (i.e., low AOF) are prone to show motive-incongruent achievement orientations when experiencing high threats. These motive-incongruent orientations are one of the reasons why state-oriented individuals under high threat develop more somatic complaints after a period of 3 months. $^{4}$

Alternative model. To test an alternative model, that motive incongruence interacts with stress to predict the course of symptoms over a period of 3 months and that state orientation mediates this direct effect, we conducted a series of separate path analyses. First, the Motive Incongruence $(\mathrm{T} 1) \times$ Threats $(\mathrm{T} 1)$ interaction (controlling for main effects) on symptoms at T2 (controlling for T1) was not significant, $\beta=.30, t(37)=1.38, p<.18$. Second, the Motive Incongruence $\times$ Threats interaction (controlling for main effects) on AOF was not significant, $\beta=-.40, t(38)=$ $-1.60, p<.12$. Thus, the results do not support the alternative model.

Additional evidence. To ascertain temporal priority of state and action orientation in the formation of motive-incongruent achievement orientations, we conducted additional analyses in the subsample of patients who completed all follow-up measures. First, the AOF $(\mathrm{T} 1) \times$ Threats $(\mathrm{T} 1)$ interaction directly affected the course of symptoms (T2, controlling for T1), $\beta=-.46, t(18)=$ $-2.50, p<.03$. Second, AOF (T1) $\times$ Threats (T1) was predictive of the course of motive incongruence (T2, controlling for T1), $\beta=$ $-.45, t(18)=-2.78, p<.02$. Third, when all predictor terms, were entered into the equation simultaneously, changes in motive incongruence (T2, controlling for T1) were predictive of the course of somatic complaints ( $\mathrm{T} 2$, controlling for $\mathrm{T} 1), \beta=.52, t(16)=$ 2.20, $p<.05$. Moreover, the direct relationship between AOF (T1) $\times$ Threats (T1) and the course of somatic complaints was no longer significant, $\beta=-.20, t(16)=-0.96, p<.35$. Thus, the mediational model obtained for motive incongruence at T1 (see Figure 6) was also valid for changes in motive incongruence over the period of 3 months. A lack of action-oriented coping with threats (i.e., SOF) was associated with increments in motive incongruence over the course of 3 months. These increments in motive incongruence mediated symptom aggravation observed in state-oriented participants under high threat. Despite the limitations due to the small sample size, the additional analyses yielded the expected pattern of results.

The alternative model, in which AOF was included as a mediator, was not supported in the subsample. Failure-related action orientation had a high stability $(r=.72, p<.01)$ over a period of 3 months. Threats, explicit achievement orientation, and/or the amount of motive-incongruent achievement orientation were not able to predict changes in action orientation.

\footnotetext{
${ }^{4}$ Using the product measure (standardized achievement orientation $\times$ standardized $n$ achievement) as an operationalization of motive congruence yielded the same significant results in the mediational model: First, AOF $\times$ Threats directly affected changes in symptoms over a period of 3 months (see above). Second, AOF $\times$ Threats was predictive of the amount of motive congruence, $\beta=.35, t(38)=2.44, p<.02$. Third, when AOF $\times$ Threats and motive congruence were entered into the equation simultaneously (controlling for main effects) motive congruence was predictive of somatic complaints at T2 (controlling for somatic complaints at T1), $\beta=$ $-.35, t(36)=-2.42, p<.03$. Moreover, the direct relationship between $\mathrm{AOF} \times$ Threats and somatic complaints was no longer significant, $\beta=$ $-.20, t(36)=-1.47, p<.15$.
} 


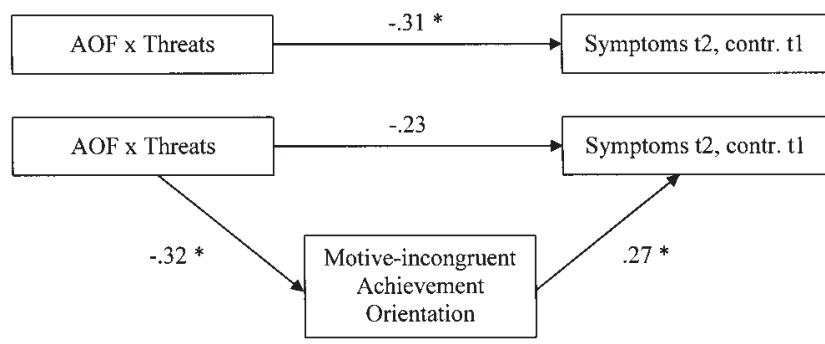

Figure 6. The mediational model with motive-incongruent achievement orientation as partially mediating the direct effect of perceived life stress (i.e., threats) and failure-related action orientation (AOF) on symptoms after 3 months (Time 2), controlling for symptoms at Time 1, in Study 2. Coefficients are standardized betas. $* p<.05$.

\section{Discussion}

Study 2 was designed to test motive-incongruent achievement orientations as a hidden stressor that mediates the course of symptoms in a clinical population undergoing treatment. The results of Study 2 support the mediational model: Motive-incongruent achievement orientations partially mediate the direct effect of a combination of low volitional control of negative affect (SOF) and excessive threats in everyday life on changes in symptoms. Study 2 findings extend Study 1 findings by demonstrating the practicability and relevance of an operant motive measure in a clinical context: Incongruence between explicit orientations and implicit motive measures not only reduces subjective well-being (Study 1) but also predicts the course of emotional and somatic complaints over a time period of 3 months (Study 2).

The mechanism by which motive incongruence may contribute to symptom formation can be explained by the effects of the stress hormone cortisol. According to this view, a strong orientation toward achievement despite an underlying emotional disinclination, as well as a failure to seek opportunities for meeting standards of excellence despite a strong achievement motive, leads to accumulation of conflict, frustrates basic needs, and increases cortisol concentration. To the extent that individuals are not aware of the motive-incongruent nature of their orientations, stress and increased cortisol concentration are likely to become chronic. Excessive exposure to cortisol has been associated with a variety of psychosomatic symptoms (Sapolsky, 1992).

The validity of motive incongruence as a mediator in the direct relationship between unfavorable conditions (state orientation and stress) and ill-being is further supported by the replication of the cross-sectional findings (Study 1) in a prospective design (Study 2 ). The prospective results of Study 2 lend further support to theory and evidence, suggesting that the construct of action versus state orientation relates to the temporal course of affective responses rather than to emotional sensitivity per se. Self-regulation is especially important when the focus is on changes in emotional well-being and somatic complaints. In contrast, personality dimensions such as neuroticism, extraversion, and anxiety describe the sensitivity or threshold for the arousal of positive and negative affect (Eysenck, 1990; Gray, 1987), that is, how quickly a person enters an emotional state. State orientation concerns the selfregulation of negative affect, that is, how quickly a person is able to leave an emotional state once it is aroused (Baumann \& Kuhl,
2002; Brunstein, 2001; Kuhl \& Beckmann, 1994b; Koole \& Jostmann, 2004). When stressful life events and symptoms are already present, self-regulatory abilities such as self-relaxation (AOF) and self-motivation (AOD) are crucial for personal health and the course of therapy.

The present findings support the assumption that the inability to downregulate negative affect (SOF) inhibits extension memory and the self so that explicit orientations become disconnected from implicit motives and the needs they represent. According to PSI theory, the functional locus of affect regulation is the implicit self system (Koole \& Jostmann, 2004; Linville, 1987; Showers \& Kling, 1996). Interventions that increase implicit self-access should help the individual to break the unhealthy cycle of negative affect, self-inhibition, and chronicity of symptoms. Consistent with this assumption, Thrash and Elliot (2002) found a concordance between implicit and self-attributed achievement motives for participants high in self-determination (presumably indicating high self-access). Conditions that foster self-determination facilitate integrative processes (Deci \& Ryan, 1991; Ryan, 1995) and are expected to support motive congruence. This hypothesis was tested in Study 3.

\section{Study 3}

The findings from the first two studies demonstrating that stress reduces motive congruence when self-regulatory abilities are low were correlational. Although the cross-sectional findings of Study 1 have been replicated in a prospective design in Study 2, one must trust that individuals can accurately report on their stress level. In addition, state-oriented individuals might be subjected to more intense stress than action-oriented individuals so that the intensity of stress rather than the self-regulatory ability might explain the results. In order to test the causal role of stress, we conducted an experiment in which stress level was manipulated: In two imagery exercises participants were asked to think of a situation with an accepting versus a threatening person and to revitalize their feelings in that situation. Imagery of an accepting person was expected to foster self-determination and the generation of motivecongruent orientations whereas imagery of a threatening person was expected to decrease motive congruence for participants with low abilities to downregulate negative affect (SOF). Because little is known about the mechanisms underlying motive incongruence, we decided to assess the implicit motive measure before the imagery exercise and the explicit measure after the exercise. The idea is that explicit reports become invalid when access to an implicit knowledge base (extension memory) is reduced by stress. In order to have a reference for the actual implicit motive, it is necessary to assess it prior to the stress manipulation (see Schultheiss \& Brunstein, 1999, for a similar approach). This approach represents just one possible conception of motive incongruence.

\section{Method}

\section{Participants}

Thirty-two participants (15 women and 17 men) were recruited through flyers at the university of Osnabrück. They participated voluntarily and were given 6.50 Euros (about 7 dollars) in return for their participation. The participants' mean age was 24.4 years (range $=20$ to 33 years). 


\section{Materials}

As in Study 1, the OMT, the MUT, and the ACS-90 were assessed. In the present sample, internal consistencies (Cronbach's alpha) were $\alpha=.82$ for AOF, $\alpha=.77$ for AOD, and $\alpha=.83$ for explicit achievement orientation. Imagery exercises were taken from Quirin (2005) As a manipulation check, six positive items (joyful, elated, merry, happy, cheerful, good-humored) and six negative items (worried, distressed, nervous, jittery, upset, anxious) were used. Internal consistencies were $\alpha=.95$ for the positive mood scale and $\alpha=.98$ for the negative mood scale.

Subjective well-being was assessed by four items of the five-item well-being index proposed by the World Health Organization (WHO, 1998). The WHO-5 is a widely used and valid measure of subjective well-being (Bonsignore, Barkow, Jessen, \& Heun, 2001; Heun, Burkart, Maier, \& Bech, 1999). Participants were asked to indicate how each of the statements applied to them "right now" (instead of "during the last two weeks"). Example items are the following: "I feel cheerful and in good spirits"; "I feel calm and relaxed." (The item "I woke up feeling fresh and rested" was not appropriate for our focus on momentary well-being.) Internal consistency was $\alpha=.80$.

A postexperimental questionnaire assessed participants' imagery experience ("The person was ...") with four acceptance items (security conveying, accepting, protecting, calming) and four threat items (threatening, anxiety arousing, frightening, upsetting). Internal consistencies were $\alpha=$ .92 for the acceptance scale and $\alpha=.66$ for the threat scale.

\section{Procedure}

Participants were tested individually. The OMT, the ACS-90, and a mood rating were given at the beginning of the experiment. Next, participants were randomly assigned to one of two imagination conditions. In the acceptance condition, they were asked to imagine a person who fully accepted them and conveyed feelings of security and support. In the threat condition, they were asked to imagine a threatening person, who made them feel insecure and anxious. Subsequently, participants were asked to listen via headphones to a 4-min prerecorded imagery exercise while sitting in a reclining chair. ${ }^{5} \mathrm{~A}$ male speaker invited listeners to close their eyes and to revitalize a concrete experience with the accepting (threatening) person. Participants were asked to imagine the person's facial expression, tone of voice, and words and to revitalize their own feelings in that situation. Subsequently, participants were asked to rate their momentary mood and to write down 10 personal goals. Participants were asked to rate their degree of commitment to each goal on a 10-point Likert scale ranging from 0 (not at all) to 9 (very much) and to indicate whether each goal was more related to achievement, affiliation, or power. Next, participants filled out the explicit achievement orientation scale (MUT) and a postexperimental questionnaire. Finally, participants were debriefed and paid for their participation. The experimental session lasted about $1 \mathrm{hr}$.

\section{Results}

\section{Manipulation Check}

Mood ratings. Hierarchical regression analyses were conducted on mood scales at T2, with mood scales at T1 entered as the first block, AOF and experimental condition entered as the second block, and their interaction term entered as the third block. There were significant main effects of experimental condition for the positive mood scale, $\beta=-.46, t(28)=-4.75, p<.01$, and the negative mood scale, $\beta=.36, t(28)=2.14, p<.05$. Dependent $t$ tests (T1 vs. T2) were calculated for each experimental condition. Participants in the acceptance condition reported significantly reduced anxiety immediately after the imagery exercise, 0.97 for $\mathrm{T} 1$ vs. 0.69 for $\mathrm{T} 2 ; t(15)=2.35, p<.05$, and, on a descriptive level, increased happiness, 1.56 for $\mathrm{T} 1$ vs. 1.75 for $\mathrm{T} 2 ; t(15)=-1.56$, $p<.14$. In contrast, participants in the threat condition reported significantly reduced happiness immediately after the imagery exercise, 1.22 for $\mathrm{T} 1$ vs. 0.85 for $\mathrm{T} 2, t(15)=3.65, p<.01$ and, on a descriptive level, increased anxiety, 0.66 for T1 vs. 1.05 for $\mathrm{T} 2, t(15)=-1.68, p<.12$. In both analyses, there were no significant (or marginally significant) main or interaction effects for AOF (all $p s>.45$ ). Thus, the experimental manipulation was effective for state- and action-oriented participants.

Imagery exercise. Hierarchical regression analyses were conducted on participants" ratings of the "to-be-imagined person" as accepting and threatening, with AOF and experimental condition entered as the first block and their interaction term entered as the second block. There were significant main effects of experimental condition for the acceptance scale, $\beta=-.81, t(29)=-7.43, p<$ .01 , and for the threat scale, $\beta=.57, t(29)=3.50, p<.01$. In the threat condition, the person was experienced as less accepting ( 0.53 for the threat condition vs. 2.34 for the acceptance condition) and more threatening ( 1.72 for the threat condition vs. 0.55 for the acceptance condition) than in the acceptance condition. In both analyses, there were no significant effects, including AOF (all $p s>.28$ ). Thus, the intensity of the imagery exercise did not differ for state- and action-oriented participants.

\section{Affect Regulation and Subjective Well-Being}

A hierarchical regression analysis was conducted on subjective well-being, with AOF and experimental condition entered as the first block and their interaction term entered as the second block. There was a significant main effect of experimental condition, $\beta=$ $-.37, t(29)=-2.19, p<.05$. Participants in the threat condition reported less subjective well-being at the end of the experiment than participants in the acceptance condition. More important, there was a significant $\mathrm{AOF} \times$ Experimental Condition interaction, $\beta=.37, t(28)=2.40, p<.03$. Unstandardized regression weights with a range of $\pm 1 S D$ for both predictor variables were used to graph this interaction effect. Consistent with expectations, state-oriented participants showed substantially lower subjective well-being at the end of the experiment after imagining a threatening person as compared with an accepting person: acceptance $M=0.41$ vs. threat $M=-1.10, t(28)=-3.37, p<.01$. Action-oriented participants were not significantly influenced in their subjective well-being at the end of the experiment by imagery conditions: acceptance $M=0.19$ vs. threat $M=0.22, t(28)=$ $0.08, p<.94$. The AOD $\times$ Experimental Condition interaction was not significant, $\beta=-.06, t(28)=-0.33, p<.75$. Findings support the hypothesis that failure-related state and action orientation moderated the influence of threatening conditions on subjective well-being at the end of the experiment.

\section{Affect Regulation and Motive Incongruence}

Achievement orientation. A hierarchical regression analysis was conducted on motive-incongruent achievement orientation (i.e., absolute difference between standardized $n$ achievement and

\footnotetext{
${ }^{5}$ We thank Markus Quirin for providing us with the materials for the imagery exercises.
} 
standardized achievement orientation) with $\mathrm{AOF}$ and experimental condition entered as the first block and their interaction term entered as the second block. There was a significant AOF $\times$ Experimental Condition interaction for motive-incongruent achievement orientation, $\beta=-.36, t(28)=-2.12, p<.05$. Unstandardized regression weights with a range of $\pm 1 S D$ for AOF were used to graph this interaction effect. As illustrated in Figure 7, the effect of the experimental manipulation on motiveincongruent achievement orientation varied as a function of state and action orientation, as predicted. State-oriented participants showed significantly higher incongruence between $n$ achievement and achievement orientation after imagining a threatening person as compared with an accepting person, $t(28)=2.52, p<.02$. In contrast, action-oriented participants did not differ in motiveincongruent achievement orientation between conditions, $t(28)=$ $-0.53, p<.60$. No other effects were significant. An additional regression analysis was conducted on achievement motive congruence, including AOD, experimental condition, and their interaction term. The AOD $\times$ Experimental Condition interaction was not significant, $\beta=.05, t(28)=0.25, p<.81$. Regression analyses provided support for the hypothesis that stress is a causal factor in the formation of motive incongruence. More specifically, threatening conditions foster motive-incongruent achievement orientations for participants high in failure-related state orientation.

Number of achievement goals. As an alternative measure of achievement orientation, the number of achievement goals that participants generated after the imagery exercise was used. A hierarchical regression analysis was conducted on motiveincongruent achievement goals (i.e., absolute difference between standardized $n$ achievement and the standardized number of

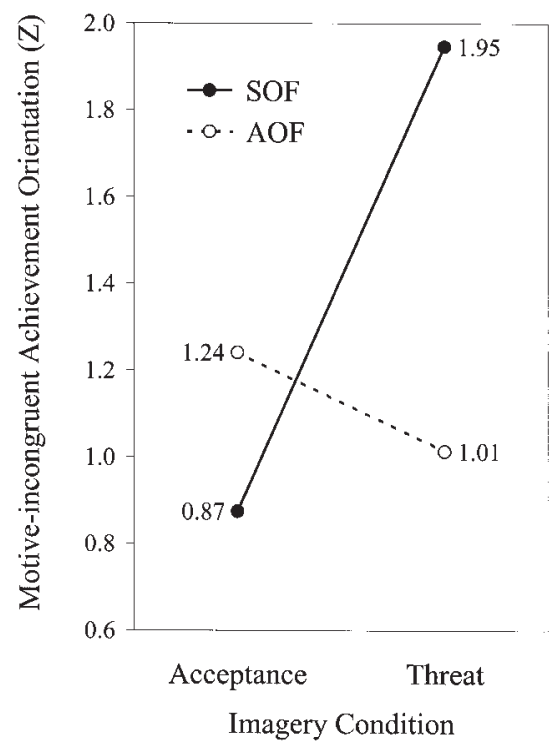

Figure 7. Incongruence (absolute difference) between implicit achievement motive and explicit achievement orientation as a function of experimental condition (i.e., imagery of an accepting vs. a threatening person) and failure-related state orientation (SOF) and action orientation (AOF) in Study 3. Low (SOF) and high (AOF) values on failure-related action orientation correspond to one standard deviation below and above the mean, respectively. achievement goals). There was a significant AOF $\times$ Experimental Condition interaction for motive-incongruent goals, $\beta=-.43$, $t(28)=-2.69, p<.02$. Unstandardized regression weights with a range of $\pm 1 S D$ for $\mathrm{AOF}$ were used to graph this interaction effect. Consistent with expectations, state-oriented participants showed higher incongruence between $n$ achievement and number of achievement goals after imagining a threatening person as compared with imagining an accepting person: acceptance $M=$ 0.78 vs. threat $M=2.05, t(28)=2.87, p<.01$. In contrast, action-oriented participants did not show a significant difference in motive-incongruent goals between imaging conditions: acceptance $M=1.20$ vs. threat $M=.76, t(28)=-0.98, p<.34$. No other effects were significant. The AOD $\times$ Experimental Condition interaction on motive-incongruent goals was not significant, $\beta=$ $.05, t(28)=0.27, p<.80$.

Commitment to achievement goals. As a third measure of achievement orientation, participants' degree of commitment toward their achievement goals was used. A hierarchical regression analysis was conducted on motive-incongruent commitment to achievement goals (i.e., absolute difference between standardized $n$ achievement and standardized commitment to achievement goals). There was a significant main effect of AOF, $\beta=-.39$, $t(29)=-2.69, p<.05$. More important, there was a significant $\mathrm{AOF} \times$ Experimental Condition interaction for motiveincongruent commitment, $\beta=-.40, t(28)=-2.64, p<.02$. Unstandardized regression weights with a range of $\pm 1 S D$ for AOF were used to graph this interaction effect. Consistent with expectations, state-oriented participants showed higher incongruence between $n$ achievement and commitment to achievement goals after imagining a threatening compared with an accepting person: acceptance $M=0.74$ vs. threat $M=2.05, t(28)=3.14$, $p<.01$. In contrast, action-oriented participants were not significantly influenced by experimental conditions: acceptance $M=$ 0.85 vs. threat $M=0.58, t(28)=-0.64, p<.53$. The AOD $\times$ Experimental Condition interaction on motive-incongruent commitment was not significant, $\beta=-.16, t(28)=-0.87, p<.39$.

\section{Motive Incongruence and Subjective Well-Being}

Achievement orientation. A hierarchical regression analysis was conducted on subjective well-being, with achievement orientation and $n$ achievement entered as the first block and their interaction term entered as the second block. There was a significant $n$ Achievement $\times$ Achievement Orientation interaction, $\beta=$ $.46, t(28)=2.70, p<.02$. Unstandardized regression weights with a range of $\pm 1 S D$ for both predictor variables were used to graph this interaction effect. As depicted in Figure 8, congruence between $n$ achievement and achievement orientation was associated with subjective well-being. In contrast, placing great importance on achievement despite low $n$ achievement scores as well as placing low importance on achievement despite high $n$ achievement scores was associated with low subjective well-being. Consistent with our hypothesis, both types of incongruence were detrimental to subjective well-being. Simple slope analyses were marginally significant for low $n$ achievement, $t(28)=-1.96, p<$ .06 , and high $n$ achievement, $t(28)=1.86, p<.08$. In an independent $t$ test, the group of 8 participants overestimating their $n$ achievement scores by at least $1 S D$ was not significantly different in their subjective well-being from the group of 8 partic- 


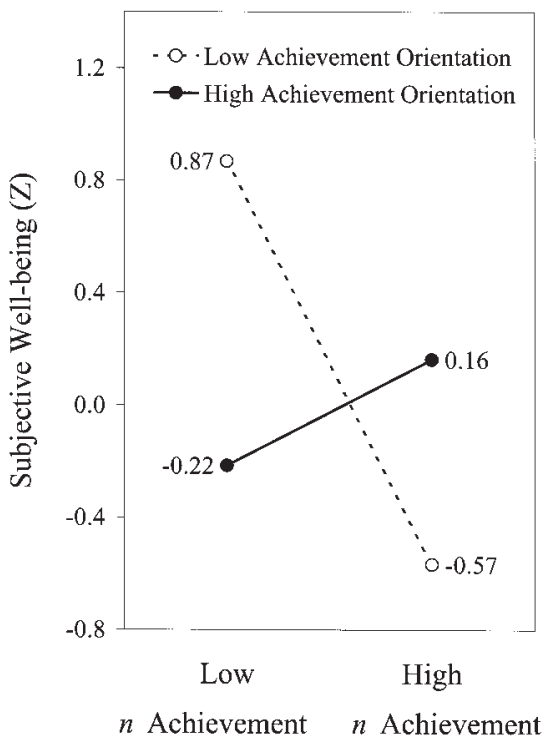

Figure 8. Subjective well-being as a function of implicit achievement motive and explicit achievement orientation in Study 3. Low and high values correspond to one standard deviation below and above the mean, respectively. $n$ Ach $=$ implicit achievement motivation.

ipants underestimating their $n$ achievement scores by at least $1 S D$ $(M=-0.26$ vs. $M=-0.89), t(14)=-1.28, p<.25$. In contrast, the congruent group had significantly higher subjective well-being $(M=.58)$ than overestimators, $t(22)=2.47, p<.03$, as well as underestimators, $t(22)=4.89, p<.01$.

Number of achievement goals. A hierarchical regression analysis was conducted on subjective well-being with number of achievement goals and $n$ achievement entered as the first block and their interaction term entered as the second block. There was a significant $n$ Achievement $\times$ Goals interaction, $\beta=.41, t(28)=$ $2.60, p<.02$. Unstandardized regression weights with a range of $\pm 1 S D$ for both predictor variables were used to graph this interaction effect. Congruence between $n$ achievement and number of achievement goals was associated with subjective well-being: low-low $M=0.95$ and high-high $M=0.01$. In contrast, striving for many achievement goals despite low $n$ achievement scores $(M=-0.22)$ as well as striving for few achievement goals despite high $n$ achievement scores $(M=-0.54)$ was associated with low subjective well-being. In an independent $t$ test, the group of six overestimators was not significantly different in their subjective well-being from the group of eight underestimators, $M=-0.22$ vs. $M=-0.46, t(12)=-0.40, p<.70$. On a descriptive level, the congruent group reported higher subjective well-being $(M=0.34)$ than overestimators, $t(22)=1.74, p<.10$, and underestimators, $t(24)=2.01, p<.06$. The difference in subjective well-being between congruent and incongruent individuals was significant, $t(30)=2.33, p<.03$.

Commitment to achievement goals. A hierarchical regression analysis was conducted on subjective well-being, with commitment to achievement goals and $n$ achievement entered as the first block and their interaction term entered as the second block. There was a significant $n$ Achievement $\times$ Commitment interaction, $\beta=$ $.41, t(28)=2.15, p<.05$. Unstandardized regression weights with a range of $\pm 1 S D$ for both predictor variables were used to graph this interaction effect. Congruence between $n$ achievement and commitment to achievement goals was associated with subjective well-being (low-low $M=0.64$ vs. high-high $M=0.14$ ). In contrast, high commitment to achievement goals despite low $n$ achievement scores $(M=-0.33)$ as well as striving for few achievement goals despite high $n$ achievement scores $(M=$ -0.53 ) was associated with low subjective well-being. In an independent $t$ test, the group of seven overestimators was not significantly different in their subjective well-being from the group of six underestimators, $M=-0.31$ vs. $M=-0.57, t(11)=$ $-0.39, p<.71$. The congruent group reported (marginally) significantly higher subjective well-being $(M=.35)$ than overestimators, $t(24)=1.68, p<.10$, and significantly higher well-being than underestimators, $t(23)=2.75, p<.02$. The difference in subjective well-being between congruent and incongruent individuals was significant, $t(30)=2.57, p<.02$.

\section{Mediational Model}

Achievement orientation. The direct effect of the AOF $\times$ Experimental Condition interaction on subjective well-being was expected to be partially mediated by motive incongruence. To test the mediational model, we completed a series of separate path analyses. First, AOF $\times$ Experimental Condition directly affected subjective well-being (see above). Second, AOF $\times$ Experimental Condition was predictive of the amount of motive-incongruent achievement orientation (see Figure 7). Third, when AOF $\times$ Experimental Condition (controlling for main effects) and motiveincongruent achievement orientation were entered into the equation simultaneously, motive-incongruent achievement orientations were predictive of subjective well-being, $\beta=-0.48, t(27)=$ $-3.21, p<.01$. Moreover, the direct relationship between AOF $\times$ Experimental Condition and subjective well-being was no longer significant, $\beta=0.20, t(27)=1.38, p<.18$. The mediational model is illustrated in Figure 9. Findings are consistent with the assumption that threatening conditions play a causal role in the formation of motive-incongruent achievement orientations for individuals with affect regulation deficits. These hidden stress factors are one of the reasons why state-oriented individuals under high threats experience less subjective well-being.

Number of achievement goals. The mediational model was significant for motive-incongruent goals: When AOF $\times$ Experi-

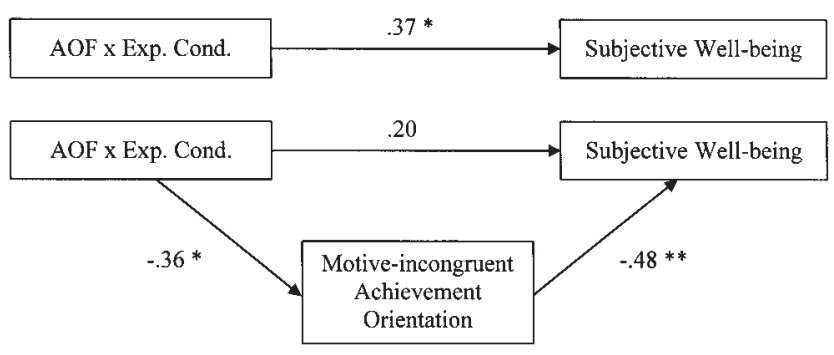

Figure 9. The mediational model with motive-incongruent achievement orientation as partially mediating the direct effect of experimental condition (exp. cond.; i.e., imagery of an accepting vs. a threatening person) and failure-related action orientation (AOF) on subjective well-being in Study 3. Coefficients are standardized betas. $* p<.05$. ** $p<.01$. 
mental Condition (controlling for main effects) and motiveincongruent goals were entered into the equation simultaneously, motive-incongruent goals were predictive of subjective well-being, $\beta=-0.38, t(27)=-2.19, p<.05$. Moreover, the direct relationship between AOF $\times$ Experimental Condition and subjective well-being was no longer significant, $\beta=.21, t(27)=1.29, p<$ .21 .

Commitment to achievement goals. The mediational model was marginally significant for motive-incongruent commitment: When AOF $\times$ Experimental Condition (controlling for main effects) and motive-incongruent commitment were entered into the equation simultaneously, motive-incongruent commitment was predictive of subjective well-being, $\beta=-0.32, t(27)=-1.75$, $p<.10$. Moreover, the direct relationship between AOF $\times$ Experimental Condition and subjective well-being was no longer significant, $\beta=.24, t(27)=1.45, p<.16$.

\section{Discussion}

Study 3 was designed to test the mediating role of motive incongruence on subjective well-being when stress is experimentally induced in a healthy population. The results of Study 3 support the mediational model: Motive-incongruent achievement orientations partially mediate the direct effect of the combination of SOF and threat on subjective well-being. Findings support the assumption that stress plays a causal role in the formation of motive-incongruent orientations. When self-regulatory abilities to cope with threatening experiences are low (SOF), participants lose access to their implicit self and are not able to generate motivecongruent orientations. In contrast, high self-regulatory abilities (AOF) can protect against the detrimental effects of stress. The manipulation check shows that intensity of the imagery exercise did not differ for state- and action-oriented participants. Thus, findings discount an alternative interpretation that stress intensity, and not self-regulatory ability, explains the results. Furthermore, findings suggest that accepting conditions presumably associated with self-determination and integrative processes (Deci \& Ryan, 1991; Ryan, 1995) may bridge the gap between implicit and explicit motives. However, on the basis of the present data, it is not possible to distinguish whether the effects are more driven by threat or acceptance. Future studies should include a neutral condition in order to test whether threat reduces congruence, acceptance promotes congruence, or both effects are significant.

The present study focused on the experimental induction of threat. Consistent with our hypothesis, failure-related action orientation (AOF) was more important in coping with threatening experiences than decision-related action orientation (AOD). Future studies may look at the causal role of demands in the formation of motive-incongruent orientations. To the extent that demanding manipulations are successful in reducing positive affect more strongly than increasing negative affect, we expect AOD to be a relevant moderator because it is associated with the ability to overcome a lack of positive affect (Koole \& Jostmann, 2004). The present results further support the assumption that action orientation is more related to affect regulation than affect sensitivity. Action-oriented participants showed the same affective response as state-oriented participants immediately after the imagery manipulation. However, action-oriented participants had overcome their negative affect by the end of the experiment. In a similar vein,
Brunstein (2001) found no difference in negative affect between SOF and AOF at the beginning of a semester, but at the end AOF was related to successful self-relaxation over the course of the semester.

Notably, the mediating role of implicit-explicit motive discrepancies was replicated for goal-motive discrepancies in the present study. Setting too many or not enough achievement goals and building too much or too little commitment to personal achievement goals is as detrimental for subjective well-being as showing too much or too little achievement orientation in self-report. The goal measures are less reactive than the explicit motive measure and further support the validity of our findings.

\section{General Discussion}

In the present research, we examined a psychological mechanism by which stressful life events may exert an influence on subjective well-being and symptom formation. Stressful life events were expected to reduce access to extended implicit networks among individuals with low abilities to volitionally control affect (i.e., state-oriented individuals) so that explicit achievement orientations are less congruent with implicit motive dispositions. By contrast, individuals with high self-regulatory abilities (i.e., actionoriented individuals) were expected to retain motive-congruent orientations even when exposed to stress. Our mediational model tested the hypothesis that motive-incongruent achievement orientations are a hidden source of stress that partially mediates the negative relationship between unattenuated stress and well-being.

In the cross-sectional Study 1, demanding life events were associated with increased achievement motive incongruence and reduced subjective well-being among state-oriented participants (SOD) in a healthy sample. Action-oriented participants (AOD) were not influenced by demands. In the longitudinal Study 2, threatening life events were associated with increased achievement motive incongruence and increased symptom formation over the course of 3 months among state-oriented participants (SOF) in a clinical sample. Action-oriented participants (AOF) were not influenced by threats. In the experimental Study 3, imagery of a threatening compared with an accepting person was found to play a causal role in increased achievement motive incongruence and reduced subjective well-being observed in state-oriented participants (SOF). In all three studies, motive incongruence in the achievement domain partially mediated the direct relationship between unfavorable conditions (state orientation by stress) and health outcomes. There were no meaningful differences between overestimators (implicit low and explicit high) and underestimators (implicit high and explicit low) in our studies. Presumably, both types of motive incongruence function as hidden stress factors.

It is noteworthy that the present research obtained converging results with two different operationalizations of stress (self-report and imagery exercise), three different measures of explicit achievement orientation (questionnaire, number of self-generated achievement goals, and goal commitment), three different health outcome measures, three different study designs (cross-sectional, longitudinal and experimental), and two different types of samples (healthy and clinical). This methodological convergence increases confidence in the robustness of our findings. Furthermore, findings point to the influence of this hidden stressor across a variety of 
settings that can be subdivided into demanding and threatening life events. Presumably, demanding events require self-motivation (AOD), whereas threatening events require self-relaxation (AOF) in order to retain motive congruence and well-being.

Motive-incongruent achievement orientations seem to play an important role in the causal chain from stressful life events to subjective ill-being and symptom formation (Kuhl, 2001; Kuhl \& Kaschel, 2004). This causal chain may be described as follows: (a) Demanding life events and difficulties in goal attainment reduce positive affect (Study 1). Trauma or threatening life events increase negative affect (Studies 2 and 3). (b) When there are no external sources of stress reduction (e.g., encouragement or consolation from others, respectively), the affective states perseverate unless the individual has developed sufficient self-regulatory competence for restoring positive affect (AOD) or reducing negative affect (AOF), respectively. (c) When this self-regulatory competence is impaired, that is, when deficits exist in the ability to self-generate positive affect (SOD) or the ability to downregulate negative affect (SOF), reduced positive affect or increased negative affect, respectively, may further perseverate (Kuhl \& Beckmann, 1994b). (d) According to the modulation assumptions of PSI theory, fixations on these affective states result in an asymmetric activation of intention memory and an inhibition of extension memory that disturb exchange between explicit and implicit modalities (Kuhl, 2001). Explicit orientations are more and more decoupled from extended experiential networks so that goals cannot be pursued in a flexible, context-sensitive manner and may not satisfy implicit needs (Rotenberg \& Arshavsky, 1988). (e) Chronic need frustration and chronic negative affect reiterate the selfinhibition cycle and may ultimately lead to symptom formation (Kuhl \& Kaschel, 2004).

The above model describes a common pathway to a variety of symptoms because chronic need frustration and unattenuated negative affect presumably increase cortisol concentration. Chronically elevated levels of this stress hormone have been associated with a variety of psychosomatic symptoms, such as eating disorder, anxiety, depression, headache, reduced immune function, and so forth (Sapolsky, 1992). Therefore, in addition to any symptomspecific causes, motive incongruence is conceived of as a general mechanism that contributes to the chronicity of frustration, negative affect, and symptoms. Mediation of this hidden stressor is expected to be only partial because life events have not only a subjective dimension but also an objective dimension that may directly influence the personality-disease relationship (cf. Van Heck, 1997). For example, a deadline for an important project may be objectively too short even when high personal investments to meet the deadline are completely congruent with an individual's implicit motive structure. Nevertheless, it would be interesting to see whether creative problem solving (Rotenberg, 1993; Rotenberg \& Arshavsky, 1988) or disengagement from unrealistic goals (Klinger, 1975) is easier in the case of motive congruence.

In conclusion, the findings reported in this article revealed a hidden source of stress that can be at least as relevant for the impairment of subjective well-being and for the formation of psychological symptoms as external stressors, namely, the discrepancy between explicit achievement concerns and implicit achievement motives. This hidden stressor reduces positive emotional states (i.e., subjective well-being) and facilitates symptom formation unless the maladaptive mood presumably associated with explicit-implicit motive discrepancies can be alleviated by selfregulatory mechanisms that improve mood without external support (i.e., by the self-motivation or self-relaxing aspects of action orientation, respectively).

\section{Limitations and Future Perspectives}

The present studies have a number of limitations. First, Studies 1 and 2 included only self-report measures as opposed to more objective measures of stress, achievement orientation, well-being, and symptom formation. Study 3 improved experimental control by manipulating stress and included achievement orientation measures that were less reactive. However, all studies relied on participant-generated outcome measures. Second, the causal role of stress was examined for threats but not for demands. Third, the effects of an experimental manipulation of threat needed to be replicated in comparison with a neutral control condition. Fourth, our experimental study investigated only one possible conception of motive incongruence, that is, that stress reduces the validity of explicit reports about enduring implicit motive dispositions (cf. Schultheiss \& Brunstein, 1999). Alternatively, one may assume that stress changes the content of both explicit and implicit motives. Our correlational Studies 1 and 2 do not allow us to distinguish between these different conceptions. In order to test the alternative conception of motive incongruence experimentally, both (implicit and explicit) motive measures must be assessed after a stress manipulation. Finally, our model was only tested in the achievement domain. Motive congruence also seems to play an important role for subjective well-being and life satisfaction in the affiliation-intimacy domain (Hofer \& Chasiotis, 2003) as well as in communion and agency (Brunstein et al., 1998). It is an interesting question for future research whether motive incongruence related to affiliation and power also contributes to the formation of psychosomatic symptoms. Need frustration may work as a "hidden stressor" irrespective of the content of frustration. However, the present data do not allow us to prematurely generalize our mediational model to other motive domains. ${ }^{6}$

The present findings show that self-regulatory abilities are an important moderator variable that can buffer against detrimental effects of stress on motive congruence: Action-oriented participants were able to adjust their explicit orientations to match implicit motives even when one is experiencing high levels of stress. Similar adaptation effects can be observed in the reduction of cognitive dissonance. For example, induction of an actionoriented mindset causes individuals who made a difficult decision

\footnotetext{
${ }^{6}$ From a theoretical perspective, the crucial role of affect regulation for motive incongruence may not generalize to other motives: Change of affect is especially relevant for the achievement motive because an achievementrelated episode typically starts with a phase of reduced positive affect (when a person is confronted with some difficulty or frustration), which changes to positive affect when the person anticipates or obtains success (McClelland, Atkinson, Clark, \& Lowell, 1953). In contrast, power and affiliation needs can also be satisfied when positive affect prevails from the outset of a motivational episode. This hypothesis can be tested in future research because it predicts that, for power and affiliation needs, emotional sensitivity (e.g., neuroticism) may be more important than affect regulation (e.g., action orientation) as a predictor of motive incongruence and well-being.
} 
to spread apart the decision alternatives more strongly, viewing the chosen more positively and the rejected more negatively, than individuals without an action-oriented mindset (Harmon-Jones \& Harmon-Jones, 2002). Presumably, this "spreading of alternatives" is motivated by affect regulation: It helps to remove negative affect associated with dissonant cognitive contents (e.g., having rejected attractive alternatives) and enables efficient implementation of the decision. Attempts to find goals that satisfy implicit needs may also be motivated by a desire to feel good and act efficiently. However, the present findings imply that successful affect regulation is a necessary prerequisite in order to be able to generate motive-congruent goals when stress is high. Participants with low abilities to downregulate negative affect (SOF) were not able to adjust their goals and attitudes. It would be interesting to see whether state-oriented participants have similar difficulties in reducing cognitive dissonance when being stressed.

Motive incongruence is conceived of as an imbalance between two cognitive systems representing implicit and explicit motives so that the communication process between systems is disturbed. In the present article, we tested the hypothesis that activation of intention memory and extension memory can be modulated by affect. Future research could also attempt to cognitively stimulate or reduce the activation of these memory systems. For example, inducing an uncompleted intention should stimulate intention memory (Goschke \& Kuhl, 1993) and inducing an analytical processing style should reduce the participation of extension memory, whereas inducing a holistic processing style should activate extension memory (Guevara, 1994). Intention and extension memory have been associated with the processing characteristics of the left and the right hemispheres, respectively (Beeman et al., 1994; Kuhl, 2001). To the extent that the lateralization hypothesis is correct, unilateral muscle contractions (e.g., squeezing a ball in one hand) could be used to stimulate the contralateral hemisphere and the associated cognitive systems (Baumann, Kuhl, \& Kazén, in press; Schiff, Guirguis, Kenwood, \& Herman, 1998). It would be interesting to see whether or not such affect-free manipulations are able to produce or reduce the hidden source of stress examined in this article, that is, motive incongruence.

\section{References}

Aiken, L. S., \& West, S. G. (1991). Multiple regression: Testing and interpreting interactions. Newbury Park, CA: Sage.

Baddeley, A. (1996). Exploring the central executive. Quarterly Journal of Experimental Psychology, 49, 5-28.

Barkley, R. A. (1997). Behavioral inhibition, sustained attention, and executive functions: Constructing a unifying theory of ADHD. Psychological Bulletin, 121, 65-94.

Baron, R. M., \& Kenny, D. A. (1986). The moderator-mediator variable distinction in social psychological research: Conceptual, strategic, and statistical considerations. Journal of Personality and Social Psychology, 51, 1173-1182.

Baumann, N., \& Kuhl, J. (2002). Intuition, affect, and personality: Unconscious coherence judgments and self-regulation of negative affect. Journal of Personality and Social Psychology, 83, 1213-1223.

Baumann, N., \& Kuhl, J. (2003). Self-infiltration: Confusing assigned tasks as self-selected in memory. Personality and Social Psychology Bulletin, 29, 487-497.

Baumann, N., Kuhl, J., \& Kazén, M. (in press). Left-hemispheric activation and self-infiltration: Testing a neuropsychological model of internalization. Motivation and Emotion.
Beckmann, J., \& Kuhl, J. (1984). Altering information to gain action control: Functional aspects of human information processing in decision-making. Journal of Research in Personality, 18, 223-279.

Beeman, M., Friedman, R. B., Grafman, J., Perez, E., Diamond, S., \& Lindsay, M. B. (1994). Summation priming and coarse semantic coding in the right hemisphere. Journal of Cognitive Neuroscience, 6, 26-45.

Beswick, G., \& Mann, L. (1994). State orientation and procrastination. In J. Kuhl \& J. Beckmann (Eds.), Volition and personality: Action versus state orientation (pp. 397-406). Göttingen, Germany: Hogrefe.

Biernat, M. (1989). Motives and values to achieve: Different constructs with different effects. Journal of Personality, 57, 69-95.

Bolte, A., Goschke, T., \& Kuhl, J. (2003). Emotion and intuition: Effects of positive and negative mood on implicit judgments of semantic coherence. Psychological Science, 14, 416-421.

Bonsignore, M., Barkow, K., Jessen, F., \& Heun, R. (2001). Validity of the five-item WHO Well-Being Index (WHO-5) in an elderly population. European Archives of Psychiatry and Clinical Neuroscience, 251, II/ 27-II/31.

Brunstein, J. C. (2001). Persönliche Ziele und Handlungs- versus Lageorientierung: Wer bindet sich an realistische und bedürfniskongruente Ziele? [Personal goals and action versus state orientation: Who builds a commitment to realistic and need-congruent goals?] Zeitschrift für Differentielle und Diagnostische Psychologie, 22, 1-12.

Brunstein, J. C., Schultheiss, O. C., \& Grässmann, R. (1998). Personal goals and emotional well-being: The moderating role of motive dispositions. Journal of Personality and Social Psychology, 75, 494-508.

Chambel, M. J., \& Curral, L. (2005). Stress in academic life: Work characteristics as predictors of student well-being and performance. Applied Psychology: An International Review, 54, 135-147.

Cox, W. M., \& Klinger, E. (2002). Motivational structure: Relationships with substance use and processes of change. Addictive Behaviors, 27, 925-940.

Damasio, A. R., Tranel, D., \& Damasio, H. C. (1991). Somatic markers and the guidance of behavior: Theory and preliminary testing (pp. 217-229). In H. S. Levin, H. M. Eisenberg, \& A. L. Benton (Eds.), Frontal lobe function and dysfunction (pp. 230-255). Oxford, England: Oxford University Press.

deCharms, R., Morrison, H., Reitman, W., \& McClelland, D. (1955). Behavioral correlates of directly measured and indirectly measured achievement motivation. In D. McClelland (Ed.), Studies in motivation. (pp. 414-423). New York: Appleton-Century-Crofts.

Deci, E. L., \& Ryan, R. M. (1991). A motivational approach to self: Integration in personality. In E. Dienstbier (Ed.), Nebraska Symposium on Motivation: Vol. 38. Perspectives on motivation (pp. 237-288). Lincoln: University of Nebraska Press.

Dieffendorf, J. M., Hall, R. J., Lord, R. G., \& Strean, M. L. (2000). Action-state orientation: Construct validity of a revised measure and its relationship to work-related variables. Journal of Applied Psychology, $85,250-263$.

Elliot, A. J. (1997). Integrating the "classic" and "contemporary" approaches to achievement motivation: A hierarchical model of approach and avoidance achievement motivation. In M. L. Maehr \& P. R. Pintrich (Eds.), Advances in motivation and achievement (Vol. 10, pp. 143-179). Greenwich, CT: JAI Press.

Elliot, A. J., Sheldon, K. M., \& Church, M. A. (1997). Avoidance personal goals and subjective well-being. Personality and Social Psychology Bulletin, 23, 915-927.

Emmons, R. A. (1986). Personal strivings: An approach to personality and subjective well-being. Journal of Personality and Social Psychology, 51, $1058-1068$.

Eysenck, H. J. (1990). Biological dimensions of personality. In L. A. Pervin (Ed.), Handbook of personality: Theory and research (pp. 244276). New York: Guilford Press. 
Folkman, S., \& Moskowitz, J. T. (2004). Coping: Pitfalls and promise. Annual Review of Psychology, 55, 745-774.

Fuhrmann, A., \& Kuhl, J. (1998). Maintaining a healthy diet: Effects of personality and self-reward versus self-punishment on commitment to and enactment of self-chosen and assigned goals. Psychology and Health, 13, 651-686.

Fuster, J. M. (1989). The prefrontal cortex. New York: Raven Press.

Goschke, T., \& Kuhl, J. (1993). The representation of intentions: Persisting activation in memory. Journal of Experimental Psychology: Learning, Memory, and Cognition, 19, 1211-1226.

Gray, J. A. (1987). The psychology of fear and stress (2nd ed.). Cambridge: Cambridge University Press.

Greenwald, A. G., \& Banaji, M. R. (1995). Implicit social cognition: Attitudes, self-esteem, and stereotypes. Psychological Review, 102, $4-27$.

Guevara, M. L. (1994). Alienation und Selbstkontrolle: Das Ignorieren eigener Gefühle [Alienation and self-control: Ignoring one's preferences]. Bern, Switzerland: Lang.

Harmon-Jones, E., \& Harmon-Jones, C. (2002). Testing the action-based model of cognitive dissonance: The effect of action orientation on postdecisional attitudes. Personality and Social Psychology Bulletin, 28, 711-723.

Heckhausen, H. (1991). Motivation and action. Heidelberg/New York: Springer-Verlag.

Heckhausen, J., \& Tomasik, M. J. (2002). Get an apprenticeship before school is out: How German adolescents adjust vocational aspirations when getting close to a developmental deadline. Journal of Vocational Behavior, 60, 199-219.

Heun, R., Burkart, M., Maier, W., \& Bech, P. (1999). Internal and external validity of the WHO Well-Being Scale in the elderly general population. Acta Psychiatrica Scandinavica, 99, 171-178.

Hofer, J., \& Chasiotis, A. (2003). Congruence of life goals and implicit motives as predictors of life satisfaction: Cross-cultural implications of a study of Zambian male adolescents. Motivation and Emotion, 27, 251-272.

Holmes, T. H., \& Rahe, R. H. (1967). The social readjustment rating scale. Journal of Psychosomatic Research, 11, 213-218.

Kazén, M., Baumann, N., \& Kuhl, J. (2003). Self-infiltration vs. selfcompatibility checking in dealing with unattractive tasks: The moderating influence of state vs. action orientation. Motivation and Emotion, 27, 157-197.

Klinger, E. (1975). Consequence of commitment to and disengagement from incentives. Psychological Review, 82, 1-25.

Klinger, E. (1993). Loss of interest. In C. G. Costello (Ed.), Symptoms of depression (pp. 43-62). New York: Wiley.

Koole, S., \& Jostmann, N. (2004). Getting a grip on your feelings: Effects of action orientation and external demands on intuitive affect regulation. Journal of Personality and Social Psychology, 87, 974-990.

Kuhl, J. (1994a). A theory of action and state orientation. In J. Kuhl \& J. Beckmann (Eds.), Volition and personality: Action versus state orientation (pp. 9-46). Göttingen, Germany: Hogrefe.

Kuhl, J. (1994b). Action versus state orientation: Psychometric properties of the Action Control Scale (ACS-90). In J. Kuhl \& J. Beckmann (Eds.), Volition and personality: Action versus state orientation (pp. 47-59). Göttingen, Germany: Hogrefe.

Kuhl, J. (1999). Der Motiv-Umsetzungs-Test (MUT) [The motiveenactment-test (MUT)]. Unpublished questionnaire, University of Osnabrück, Osnabrück, Germany.

Kuhl, J. (2000). A functional-design approach to motivation and volition: The dynamics of personality systems interactions. In M. Boekaerts, P. R. Pintrich, \& M. Zeidner (Eds.), Self-regulation: Directions and challenges for future research (pp. 111-169). New York: Academic Press. Kuhl, J. (2001). Motivation und Persönlichkeit: Interaktionen psychischer
Systeme [Motivation and personality: Interactions of mental systems]. Göttingen, Germany: Hogrefe.

Kuhl, J., \& Baumann, N. (2000). Self-regulation and rumination: Negative affect and impaired self-accessibility. In W. Perrig \& A. Grob (Eds.), Control of human behavior mental processes and consciousness: Essays in honor of the 60th birthday of August Flammer (pp. 283-305). Mahwah, NJ: Erlbaum.

Kuhl, J., \& Beckmann, J. (1994a). Alienation: Ignoring one's preferences. In J. Kuhl \& J. Beckmann (Eds.), Volition and personality: Action versus state orientation (pp. 375-390). Göttingen, Germany: Hogrefe.

Kuhl, J., \& Beckmann, J. (1994b). Volition and personality: Action versus state orientation. Göttingen, Germany: Hogrefe.

Kuhl, J., \& Helle, P. (1986). Motivational and volitional determinants of depression: The degenerated-intention hypothesis. Journal of Abnormal Psychology, 95, 247-251.

Kuhl, J., \& Henseler, W. (2003). Entwicklungsorientiertes Scanning (EOS). [Development-oriented scanning (EOS)]. In L. V. Rosenstiel \& J. Erpenbeck (Eds.), Handbuch der Kompetenzmessung [Handbook of competence measurement] (pp. 428-453). Heidelber, Germany: Schäffer-Poeschel.

Kuhl, J., \& Kaschel, R. (2004). Entfremdung als Krankheitsursache: Selbstregulatioin von Affekten und integrative Kompetenz [Alienation as a determinant of symptom formation: Self-regulation of affect and integrative competence]. Psychologische Rundschau, 55, 61-71.

Kuhl, J., \& Kazén, M. (1994). Self-discrimination and memory: State orientation and false self-ascription of assigned activities. Journal of Personality and Social Psychology, 66, 1103-1115.

Kuhl, J., \& Kazén, M. (1999). Volitional facilitation of difficult intentions: Joint activation of intention memory and positive affect removes stroop interference. Journal of Experimental Psychology: General, 128, 382399.

Kuhl, J., \& Scheffer, D. (1999). Der operante Multi-Motiv-Test (OMT): Manual [The operant multi-motive-test (OMT): Manual]. University of Osnabrück, Osnabrück, Germany.

Linville, P. W. (1987). Self-complexity as a cognitive buffer against stress-related illness and depression. Journal of Personality and Social Psychology, 52, 663-676.

Martin, L. L., \& A. Tesser (1996). Striving and feeling: Interactions among goals, affect, and self-regulation. Mahwah, NJ: Erlbaum.

McClelland, D. (1980). Motive dispositions: The merits of operant and respondent measures. In L. Wheeler (Ed.), Review of personality and social psychology (Vol. 1, pp. 10-41). Beverly Hills: Sage.

McClelland, D. C., Atkinson, J. W., Clark, R. A., \& Lowell, E. L. (1953). The achievement motive. New York: Appleton-Century-Crofts.

McClelland, D. C., Koestner, R., \& Weinberger, J. (1989). How do self-attributed and implicit motives differ? Psychological Review, 96, 690-702.

Murray, Н. А. (1943). Thematic Apperceptive Test manual. Cambridge, MA: Harvard University Press.

O'Connor, B. P. (1998). All-in-one programs for exploring interactions in moderated multiple regression. Educational and Psychological Measurement, 58, 833-837.

Quirin, M. (2005). The self and the regulation of negative affect. Unpublished doctoral dissertation, University of Osnabrück, Germany.

Renner, M. J., \& Mackin, R. S. (1998). A life stress instrument for classroom use. Teaching of Psychology, 25, 46-48.

Rotenberg, V. S. (1993). Richness against freedom: Two hemisphere functions and the problem of creativity. European Journal for High Ability, 4, 11-19.

Rotenberg, V. S., \& Arshavsky, V. V. (1988). The two hemispheres and the problem of psychotherapy. Dynamische Psychiatrie, 20, 369-377.

Rothermund, K., \& Meiniger, C. (2004). Stress-buffering effects of selfcomplexity: Reduced affective spillover or self-regulatory processes? Self and Identity, 3, 263-282. 
Ryan, R. M. (1995). Psychological needs and the facilitation of integrative processes. Journal of Personality, 63, 397-427.

Sapolsky, R. M. (1992). Stress, the aging brain, and the mechanism of neuron death. Cambridge, MA: MIT Press.

Scheffer, D. (2005). Implizite Motive [Implicit motives]. Göttingen, Germany: Hogrefe.

Scheffer, D., Kuhl, J., \& Eichstaedt, J. (2003). Der Operante Motiv-Test (OMT): Inhaltsklassen, Auswertung, psychometrische Kennwerte und Validierung [The operant motive test (OMT): Contents, scoring, psychometric values, and validation] In J. Stiensmeier-Pelster \& F. Rheinberg (Eds.), Diagnostik von Motivation und Selbstkonzept [Diagnostic of motivation and self-concept] (pp. 151-167). Göttingen, Germany: Hogrefe.

Schiff, B. B., Guirguis, M., Kenwood, C., \& Herman, C. P. (1998). Asymmetrical hemispheric activation and behavioral persistence: Effects of unilateral muscle contractions. Neuropsychology, 12, 526-532.

Schultheiss, O. C., \& Brunstein, J. C. (1999). Goal imagery: Bridging the gap between implicit motives and explicit goals. Journal of Personality, 67, 1-38.

Scully, J. A., Tosi, H., \& Banning, K. (2000). Life event checklists: Revisiting the social readjustment rating scale after 30 years. Educational and Psychological Measurement, 60, 864-876.

Sheldon, K. M., \& Kasser, T. (1995). Coherence and congruence: Two aspects of personality integration. Journal of Personality and Social Psychology, 68, 531-543.

Showers, C. J., \& Kling, K. C. (1996). Organization of self-knowledge: Implications for recovery from sad mood. Journal of Personality and Social Psychology, 70, 578-590.
Spangler, W. D. (1992). Validity of questionnaire and TAT measures of need for achievement: Two meta-analyses. Psychological Bulletin, 112, $140-154$.

Thrash, T. M., \& Elliot, A. J. (2002). Implicit and self-attributed achievement motives: Concordance and predictive validity. Journal of Personality, 70, 729-755

Van Heck, G. L. (1997). Personality and physical health: Toward an ecological approach to health-related personality research. European Journal of Personality, 11, 415-433.

Wheeler, M. A., Stuss, D. T., \& Tulving, E. (1997). Toward a theory of episodic memory: The frontal lobes and autonoetic consciousness. Psychological Bulletin, 121, 331-354.

Winter, D. G. (1991). Manual for scoring motive imagery in running text (3rd ed.). Unpublished manuscript, University of Michigan, Department of Psychology.

Winter, D. G. (1996). Personality: Analysis and interpretation of lives. New York: McGraw-Hill.

World Health Organization. (1992). The ICD-10 classification of mental and behavioural disorders: Clinical descriptions and diagnostic guidelines. Geneva, Switzerland: Author.

World Health Organization: Regional Office for Europe. (1998, August) Well-being measures in primary health care: The DepCare Project. Consensus Meeting, Stockholm, Sweden.

Received July 14, 2003

Revision received May 11, 2005

Accepted May 23, 2005

\section{New Editor Appointed, 2007-2012}

The Publications and Communications (P\&C) Board of the American Psychological Association announces the appointment of a new editor for a 6-year term beginning in 2007. As of January 1, 2006, manuscripts should be directed as follows:

- Emotion (www.apa.org/journals/emo.html), Elizabeth A. Phelps, PhD, Department of Psychology, New York University, 6 Washington Place, Room 863, New York, NY 10003.

Electronic manuscript submission. As of January 1, 2006, manuscripts should be submitted electronically via the journal's Manuscript Submission Portal (see the Web site listed above). Authors who are unable to do so should correspond with the editor's office about alternatives.

Manuscript submission patterns make the precise date of completion of the 2006 volumes uncertain. The current editors, Richard J. Davidson, PhD, and Klaus R. Scherer, PhD, will receive and consider manuscripts through December 31, 2005. Should 2006 volumes be completed before that date, manuscripts will be redirected to the new editor for consideration in 2007 volume. 